\title{
Synthesis, chemistry and applications of 5-hydroxymethylfurfural and its derivatives
}

\author{
Jarosław Lewkowski
}

Department of Organic Chemistry, University of Łódź, Narutowicza 68, 90-136 Łódź, POLAND E-mail: JLEWKOW@,krysia.uni.lodz.pl

(received 26 Jun 05; accepted 31 Jul 01; published on the web 08 Aug 01)

Contents

Introduction

PART A. 5-HYDROXYMETHYLFURFURAL (HMF)

1. A historical outline of studies on 5-hydroxymethylfurfural (HMF)

2. Aspects of the synthesis of HMF

2.1. The mechanism of the fructose dehydration

2.2. The kinetics of the HMF synthesis

3. Chemical conversions of HMF

3.1. Reactions of the Hydroxymethyl Group

3.1.1. The formation of esters

3.1.2. The formation of ethers

3.1.3. The formation of halides

3.1.4. The oxidation

3.2. Reactions of the Formyl Group

3.2.1. The reduction

3.2.2. Condensation reactions

3.2.3. Oxidation reactions

3.3. Reactions of the furan ring

3.4. The polymerisation of HMF

3.5. Electrochemical conversions of HMF

PART B. 2,5-FURANDICARBALDEHYDE (FDC)

4. The Synthesis of 2,5-Furandicarbaldehyde (FDC)

5. The Chemistry and Applications of 2,5-Furandicarbaldehyde (FDC)

PART C. 2,5-FURANDICARBOXYLIC ACID (FDCA)

6. Methods for Synthesis of 2,5-Furandicarboxylic Acid (FDCA)

7. The Chemistry and Applications of 2,5-Furandicarboxylic Acid (FDCA)

Conclusions

References 


\section{Introduction}

The prospect of exciting research activity in the chemistry of furfural derived compounds such as 5-hydroxymethylfurfural (HMF), 2,5-furandicarbaldehyde and 2,5-furan-dicarboxylic acid prompted the writing of this article. As the field of application of these compounds is really enormous, it is no wonder that research in this area, starting at the end of $19^{\text {th }}$ century, is still being developed. Numerous important scientific groups are carrying out studies on the synthesis, and applications of HMF and its derivatives. Notable among these are, Gaset (Toulouse), Descotes (Lyon), Lichtenthaler (Darmstadt), and Gelas (Clermont-Ferrand). Not only academic scientists are interested in this subject, the chemical industry, is represented by sugar companies such as Beghin-Say, and Süddeutsche Zucker. Despite this interest, there are not many comprehensive monographs or reviews covering the chemistry of HMF. Two classic reviews, by Newth $^{1}$ and by Feather and Harris, ${ }^{2}$ appeared in 1951 and 1973 respectively. Reviews by Gaset et al., ${ }^{3}$ Faury et al. $^{4}$ and by Kuster ${ }^{5}$ are more recent, but they are not detailed. An important review review by Cottier and Descotes ${ }^{6}$ appeared in 1991.

This review is written to update those above, to summarize the contributions of the last 100 years; and to emphasize recent developments especially in electrochemistry, and on dialdehyde and diacid chemistry.

\section{PART A. 5-HYDROXYMETHYLFURFURAL (HMF)}

\section{A historical outline of studies on 5-hydroxymethylfurfural (HMF)}

5-Hydroxymethylfurfural (HMF) 1 has been of interest since the last decade of the $19^{\text {th }}$ century. In 1895 Düll $^{7}$ and Kiermeyer ${ }^{8}$ working independently, published a method of synthesis and chemical reactions of the compound, which they called "oxymethylfurfurol".

Later on, British chemists started their conquest; Fenton, ${ }^{9}$ Gostling ${ }^{10}$ and Robinson ${ }^{11}$ published the results of their studies on HMF. In 1919, Middendorp ${ }^{12}$ presented the full and the detailed study concerning the synthesis, the physical characterisation and the chemical behaviour of HMF.

Several years later other authors published their results, as for example Reichstein ${ }^{13,14}$ and Haworth and Jones ${ }^{15}$ - especially the latter brought immense progress in the chemistry of HMF. They worked out the modern method of its synthesis and studied the mechanism of its formation. From among a great number of papers concerning the chemistry of HMF, Karashima's article is worth mentioning. ${ }^{16} \mathrm{He}$ worked out the method of synthesis of 5-acetoxymethylfurfural directly from HMF and fully characterised this compound. He reported also the formation of 5hydroxymethylfurfurylideneacetic acid by the Perkin condensation of HMF with acetic anhydride.

Till now, over 1000 papers have been published, which is a proof for the great importance of this kind of compounds. It is not possible in this work to quote all of these articles, but some reviews are worth mentioning. In the "Advances in Carbohydrate Chemistry" series, two articles were published, first by Newth ${ }^{1}$ in 1951, the second appeared 20 years later by Feather. ${ }^{2}$ Moye $^{17}$ has written a review describing methods of the preparation and industrial applications of HMF. 
Later, in the 80's, two papers were published; Gaset et $a l^{3}$ reviewed industrial methods of the preparation of HMF, Faury ${ }^{4}$ dealt with newest chemical conversions of this compound.

Recently, Kuster ${ }^{5}$ as well as Cottier and Descotes ${ }^{6}$ have summarised the last 30 years of HMF chemistry. As for the application of 5-hydroxymethylfurfural in the polymer chemistry, Moore and Kelly ${ }^{18}$ and ten years later Gandini ${ }^{19}$ reviewed this problem.

\section{Aspects of the synthesis of HMF}

The synthesis of HMF is based on the triple dehydration of hexoses. Various substrates can be used: hexoses themselves, oligo- and polysaccharides as well as converted industrial wastes ${ }^{20}$. The acid catalysed dehydration leads, apart from HMF to various side-products (Scheme 1).

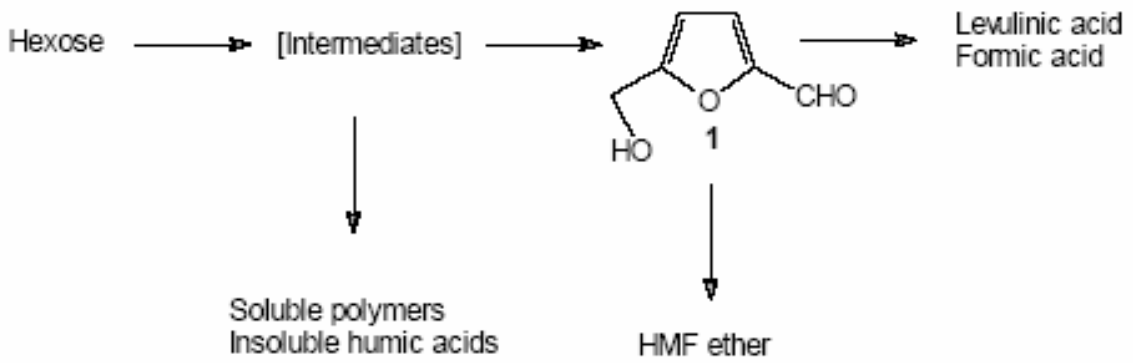

\section{Scheme 1}

Looking at the Scheme 1, one could have an impression that the synthesis of HMF is very simple. But studies performed by a number of independent scientists demonstrated that the chemistry of the formation of HMF is very complex; it includes a series of side-reactions, which influence strongly on the efficiency of the process. The decomposition to levulinic acid and the polymerisation to humic acids are the most important factors decreasing the yield of HMF.

The Scheme 1 is a general one and shows only the most representative products. Antal et al. ${ }^{21}$ analysed very profoundly the reaction of sugar decomposition in an aqueous solution and they found four groups of products formed in the course: the isomerisation, the dehydration, the fragmentation and the condensation. Van $\operatorname{Dam}^{22}$ and Cottier ${ }^{23}$ showed that the aqueous and nonaqueous processes led to about 37 products. They demonstrated that the reactions carried out in an aqueous medium provoked the degradation of $\mathrm{HMF}$ and that the polymerisation occurred in both aqueous and non-aqueous media.

\subsection{The mechanism of the fructose dehydration}

As it has been already mentioned, Haworth and Jones ${ }^{15}$ were the first to suggest the mechanism of the dehydration of fructose leading to HMF. Modern studies performed by Van Dam ${ }^{22}$, Kuster $^{5}$ and Antal ${ }^{21}$ showed that the dehydration of hexoses (especially fructose and glucose) went through one of two possible pathways (Scheme 2). Path ' $a$ ' included the transformation of ring systems, while the path ' $b$ ' is based on acyclic compounds.

$\mathrm{Antal}^{21}$ proved experimentally that the mechanism of the HMF formation went through cyclic intermediates. The most significant evidence is:

- Easy formation of HMF from fructose or a fructose part of sucrose

- 2,5-Anhydro-D-mannose converts easily into $\mathrm{HMF}^{1}$. This compound is a parent aldehyde 
to the enol 2.

- When the reaction was carried out in $\mathrm{D}_{2} \mathrm{O}$ starting from fructose, deuterium was absent in HMF. If 3-deoxyglycosulose 3 formed in the course of the reaction, one should expect a carbondeuterium bond due to the keto-enol tautomerism².

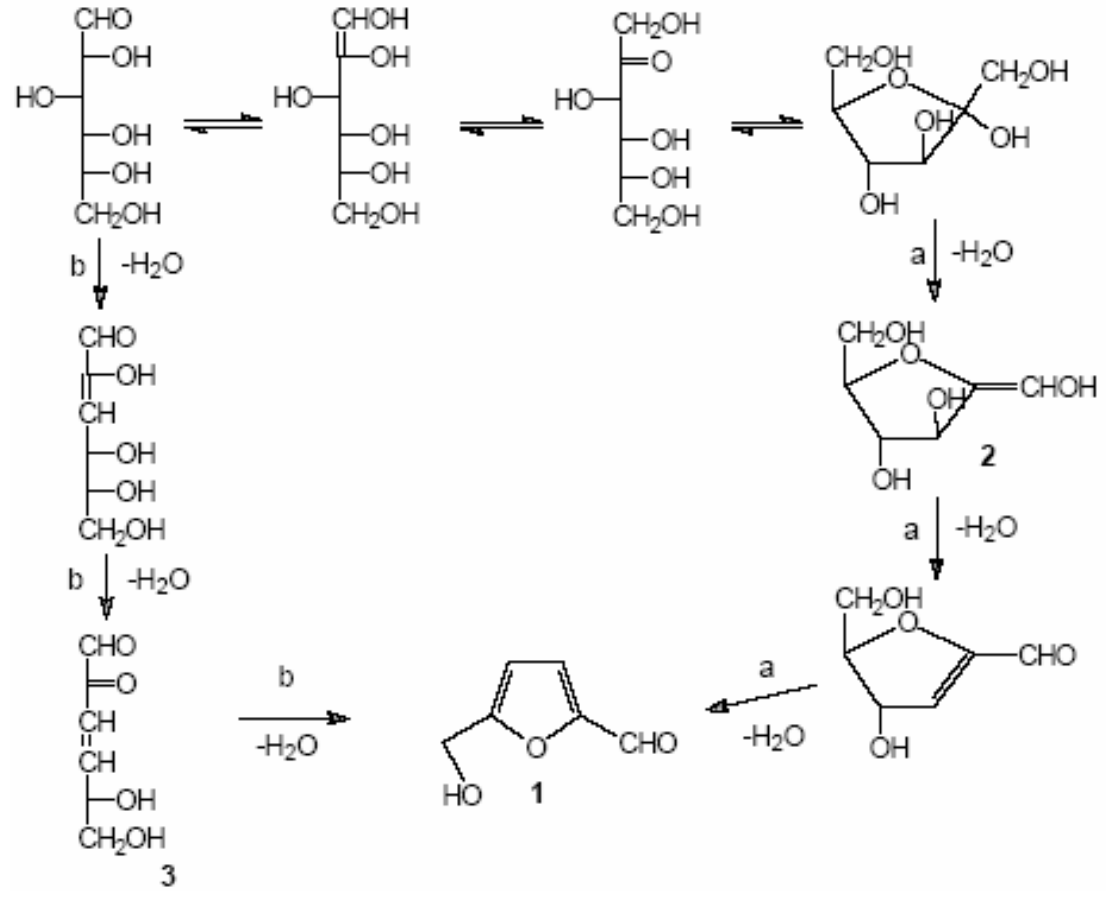

Scheme 2

\subsection{The kinetics of the HMF synthesis}

All described methods of the synthesis of HMF require the utilisation of the thermal dehydration of hexoses in acidic medium. These conditions cause some difficulties in isolation of HMF, especially as HMF is a very active and unstable compound. Kuster ${ }^{5}$ established factors determining the rate of the formation of HMF:

-The sort of the substrate and the hydrolysis degree

-The kind and the concentration of a catalyst

-The time and the temperature of the reaction

- The concentration of a polymer and the rate of the polymerisation

-The type of solvent and the stability of HMF in given conditions

The synthesis is more efficient and more selective when started from ketohexoses than from aldohexoses. For example, the hydrolysis of sucrose in an aqueous medium is much faster than the dehydration and a glucose part is always present in a post-reaction mixture. It is to state that due to a greater stability of the structure of glucose, it enolyses in a very low degree and the enolisation is a determining factor of the HMF formation from glucose (Scheme 2). Moreover, glucose can condense to form oligosaccharides bearing reducing groups, which may react with intermediates or with HMF itself. This would result in a cross-polymerisation. Despite, glucose is still utilised in industry for the preparation of HMF because of its price lower than fructose ${ }^{6}$. 
The dehydration of hexoses is catalysed by protonic acids as well as by Lewis acids. First syntheses of HMF were catalysed by oxalic acid ${ }^{7,8,12,15}$ and till now nearly one hundred inorganic and organic compounds were positively qualified as catalysts for the HMF synthesis. Cottier ${ }^{6}$ divided catalysts into five groups; they are collected in Table 1.

Iodine catalysis allowed performing the dehydration even from aldohexoses. Bonner et al. $^{24,25}$ using this method, converted sucrose into HMF in $20 \%$ yield. Morikawa ${ }^{26}$ utilised iodine as a catalyst to obtain HMF in $64 \%$ yield.

Table 1. Group of Catalysts

\begin{tabular}{|c|c|c|c|c|}
\hline Organic acids & Inorganic acids & Salts & Lewis acids & Others \\
\hline Oxalic acid & Phosphoric acid & $\left(\mathrm{NH}_{4}\right)_{2} \mathrm{SO}_{4} / \mathrm{SO}_{3}$ & $\mathrm{ZnCl}_{2}$ & Ion-exchange resins \\
\hline Levulinic acid & Sulphuric acid & Pyrid/ $/ \mathrm{PO}_{4-3}$ & $\mathrm{AlCl}_{3}$ & Zeolites \\
\hline Maleic acid & Hydrochloric acid & Pyrid/HCl & $\mathrm{BF}_{3}$ & \\
\hline \multirow[t]{9}{*}{$\mathrm{p}-\mathrm{TsOH}$} & Iodine or & Aluminium salts & & \\
\hline & $\begin{array}{l}\text { Hydroiodic acid } \\
\text { generated in situ }\end{array}$ & Th and $\mathrm{Zr}$ ions & & \\
\hline & & Zirconium phosphate & & \\
\hline & & Ions: $\mathrm{Cr}, \mathrm{Al} ., \mathrm{Ti}, \mathrm{Ca}$, & & \\
\hline & & In & & \\
\hline & & $\mathrm{ZrOCl}_{2}$ & & \\
\hline & & $\mathrm{Vo}\left(\mathrm{SO}_{4}\right)_{2}, \mathrm{TiO}_{2}$ & & \\
\hline & & V-porphyrine & & \\
\hline & & $\mathrm{Zr}$, Cr, Ti-porphyrine & & \\
\hline
\end{tabular}

The use of organic and inorganic salts in the synthesis of HMF was the subject of numerous works. Mednic ${ }^{27,28}$ proposed to utilise ammonium phosphates (the yield 23\%), triethylamine phosphate $(36 \%)$ or pyridinium phosphate. The latter allowed obtaining HMF in $44 \%$ yield. Nakamura $^{29}$ invented the catalysis with zirconium phosphate and zirconyl chloride, a further development of this method ${ }^{30}$ allowed improving the yield up to $90 \%$.

Fayet and Gelas ${ }^{31}$ utilised various pyridinium salts: poly-4-vinylpyridinium hydrochloride as well as pyridinium trifluoroacetate, hydrochloride, hydrobromide, perbromate and ptoluenesulfonate. Starting from fructose, they obtained HMF in 70\% average yield.

Smith $^{32}$ as well as Garber and Jones ${ }^{33}$ proposed utilising ammonium sulphate; Hales et al. ${ }^{34}$ as well as scientists from Atlas Powder Lab. ${ }^{35}$ applied chromium trichloride or zinc chloride.

Works concerning the application of ion-exchange resins for the synthesis of HMF are the most numerous. Nakamura ${ }^{36}$ investigated the influence of a strongly acidic ion exchange resin and obtained HMF in $80 \%$ yield. Gaset et al. ${ }^{37,38}$ utilised Levatit ${ }^{\circ}$ SPC-108, to form HMF in $70-80 \%$ yield. Researchers from Noguchi Institute ${ }^{39}$ patented the use of ion-exchange resins such as Amberlite $\AA$ IR-116 or Diaion $\AA$ PK-228 cross-linked with divinylbenzene. Some authors ${ }^{40,41}$ claimed Diaion ${ }^{\circledR}$ PK-216 to be the most efficient. In both cases HMF was obtained in $90 \%$ yield. Apart from the methods described above, it is worth to mention works by Mercadier, ${ }^{42}$ 
Rigal, ${ }^{43}$ El-Hajj ${ }^{44}$ or Rapp. ${ }^{20}$ Their syntheses were also based on ion exchange and gave HMF in high yields.

The type of solvent and its influence on the efficiency of the dehydration is closely connected with temperature conditions. Cottier ${ }^{6}$ divided methods into 5 groups depending on the type of solvent and the temperature of the process:

-Aqueous processes carried out at temperatures below $200{ }^{\circ} \mathrm{C}$

-Aqueous processes carried out at temperatures over $200{ }^{\circ} \mathrm{C}$

-Processes in non-aqueous medium

-Processes in mixed solvents

-Processes without solvent and microwave processes

The methods belonging to the first group are very convenient in the ecological point of view, but unfortunately they are not very efficient. Studies performed by laboratories of Suddeutsche Zucker showed that the maximum yield of HMF obtained via Rapp's procedure ${ }^{20}$ is about $30 \%$. Cottier $^{45}$ reported that the application of ion-exchange resins in an aqueous medium allowed formation of HMF in satisfactory yield. Depending on the mode of the isolation, he obtained it in $28 \%$ or $26 \%$ yield. They observed no influence of high dilution on the efficiency.

The second group of methods is based on pyrolitic processes. It was noted that the yield was increased in these reactions up to $58 \%$ and that the time of the reaction was shortened. Soluble polymeric products were detected instead of insoluble humic acids. Non-aqueous solvents require high dilution system; owing to the hydrophilic character of reagents. Various solvents were tested: Bonner ${ }^{24,25}$ and Shur et al. ${ }^{46}$ carried out the reaction in DMF, Brown ${ }^{47}-$ in acetonitrile. Morikawa ${ }^{26}$ proposed the application of quinoline and Smythe and Moye ${ }^{48,49}$ performed the reaction in polyglycol ethers. The greatest number of papers described the utilisation of DMSO as a solvent in the HMF synthesis. Nakamura, ${ }^{29,30,36}$ Noguchi Institute ${ }^{39}$ and Gaset et al. ${ }^{37,38}$ carried out reactions catalysed by ion exchange resins in DMSO. Mussau ${ }^{50}$ performed the reaction without a catalyst, carrying it out in DMSO, too. Problems concerning the solubility of hexoses in organic solvents were resolved by the application of mixed-solvent (water-organic) systems. Chemists worked on these methods for a long time, Teunissen ${ }^{51}$, in 1931 proposed to use homogeneous systems for the synthesis of HMF. Now numerous papers describing various mixed systems have appeared. Peniston ${ }^{52}$ utilised n-butanol, Mednic ${ }^{27,28}$ and Hales $^{34}$ dioxane. Atlas Powder Co Laboratories ${ }^{35}$ and Kuster ${ }^{53-56}$ tested polyethylene glycols. The last method allowed a decrease in the degree of HMF degradation to levulinic acid.

Reactions run without a solvent resulted in diminished formation of levulinic acid and humic acids. Fayet and Gelas ${ }^{31}$ worked with equimolar amounts of hexoses and pyridinium salts to obtain HMF in $70 \%$ yield. Neyret ${ }^{57}$ tested the use of lower amounts of pyridinium salts other than those used by Fayet and Gelas. The best results were obtained with pyridinium oxalate, although the yield did not exceed $20 \%$, the ecological value of this method allowed using it in an industrial scale. Cottier ${ }^{45}$ worked out a nice, clean and efficient laboratory method of preparation of HMF. According to his description the irradiation with microwaves of aqueous fructose (or sucrose) mixed with inorganic phosphates for 3 minutes gave HMF in $28 \%$.

Chemists continue studies on HMF synthesis. Ponder and Richards ${ }^{58}$ tested the chemical behaviour of D-glucose in the vacuum pyrolysis conditions, in the presence of such salts as 
sodium chloride, calcium acetate, and bases such as sodium or calcium hydroxide. The reaction lasted 30 minutes and it led to several anhydro-fructofuranoses and to HMF. Nakama et al. ${ }^{59}$ studied the reaction of various disaccharides and monosaccharides such as: $O^{4}-\beta-D-$ galactopyranosyl-D-glucose, $\mathrm{O}^{4}-\beta$-D-glucopyranosyl-D-glucose, D-mannose, D-glucose and Dgalactose with phenylalanine. All reactions were carried out in water, at $98{ }^{\circ} \mathrm{C}$ and lasted 10 hours leading to 5 -hydroxymethylfurfural in fair yield. Salomon and co-workers ${ }^{60}$ tested catalytic properties of tributylstannoxane in the hydrolysis of 5-acetoxymethylfurfural. The reaction was carried out in benzene for 8 hours at $80{ }^{\circ} \mathrm{C}$ and led to HMF in $92 \%$ yield. The reaction of 2 amino-D-2-deoxyglucose hydrochloride ${ }^{61}$ was carried out in mixed solvents with a tellurium buffer at $130^{\circ} \mathrm{C}$ for $4 \frac{1}{2}$ hours and led to 5-hydroxymethylfurfural. Grin et al. ${ }^{62}$ studied the conversion of fructose without a solvent leading to HMF. They tested various temperatures and various times of the reaction. The best results were obtained when the reaction lasted 70 minutes and was carried out at $74{ }^{\circ} \mathrm{C}$. Some physico-chemical studies were performed also by Isaacs and Coulson. ${ }^{63}$ Chmielewski et al. $^{64}$ oxidised 2,5-bis-(hydroxymethyl)furan with pyridinium dichromate in dichloromethane to obtain HMF in around 50\% yield after 24 hours of the

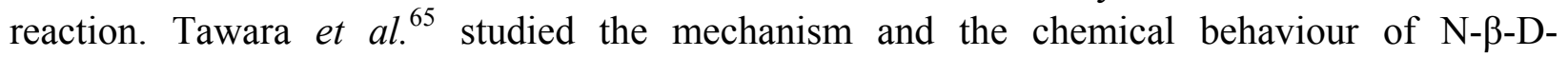
glucopyranosyl-3-chloro-4-methylaniline in the reaction catalysed by potassium pyrosulfite under microwave irradiation. This reaction also gave HMF in satisfactory yield.

Serious attempts have been made to the isolation of 5-hydroxymethylfurfural from natural

products. Numerous scientists tested numerous vegetal materials: Ichikawa ${ }^{66}$ carried out the extraction of Ubai drug from Prunus mume, Fernandez ${ }^{67}$ extracted it with hot water from Bryothamnion trignetrum. Numata et al. ${ }^{68}$ isolated 5-hydroxymethylfurfural from Osmunda japonica, Ayer ${ }^{69}$ reported its isolation from malt extract. Shimizu ${ }^{70}$ performed the extraction of Campo medicinae and Hsiao ${ }^{71}$ obtained HMF from Aralia bipinata.

The problem with the efficient preparation of pure 5-hydroxymethylfurfural is still unresolved. That is why, chemists keep on working on this subject developing new technologies of its synthesis, especially that the field of its application is immense. It is to state that despite numerous methods, which are being reported, no one has found an inexpensive and easy-to-use mode of the preparation of this compound.

\section{Chemical conversions of HMF}

From among more than thousand papers concerning HMF, the majority describe the methodology of its synthesis. But it does not mean that studies on its chemical behaviour were neglected - just the opposite, a significant number of serious papers contributed to this topic. These results confirmed the great importance of 5-hydroxymethylfurfural in various branches of the fundamental and applied chemistry.

\subsection{Reactions of the hydroxymethyl group}

The hydroxymethyl group in HMF behaves in a way typical for primary alcohols bearing an aromatic moiety. Thus, it can be compared with benzyl or furfuryl alcohol.

\subsubsection{The formation of esters}

The acetylation of HMF with acetic acid can lead to triacetates or monoacetates, which was discovered by Fenton ${ }^{10}$ and Blanksma. ${ }^{72}$ But 5 -acetoxymethylfurfural 4 was obtained most easily in the reaction of HMF with acetic anhydride. ${ }^{10,16} 5$-Propionoxymethylfurfural $\mathbf{5}$, a fungicide 
used much in textile, food and tanning industries ${ }^{12,73-75}$ was obtained using two methods ${ }^{76}$. The first required 15 hours of heating of HMF with propionic anhydride, and in the second, propionic acid was reacted with HMF in the presence of sulphuric acid. (Scheme 3)

Kiermeyer $^{8}$ reported the synthesis of 5-benzoyloxymethylfurfural 6 in the reaction of HMF with benzoyl chloride catalysed by sodium hydroxide.

Recent years brought two patents concerning two methods of the esterification of HMF. The first $^{77}$ involved the action of acetic anhydride on HMF in the presence of DMAP as a catalyst; the second $^{41}$ exploited the use of sodium salts as catalysts for the reaction of HMF with carboxylic acid anhydrides.

\subsubsection{The formation of ethers}

Kiermeyer $^{8}$ discovered that upon heating HMF in an acidic medium, some 5,5'-diformylfurfuryl ether 7 was found. Chemists started to investigate this problem, after Cram's article ${ }^{78}$ appeared, he reported that HMF condensed with diols yielding polyfuran ethers having strong complexing properties. Thus, two efficient methods of ether 7 preparation ${ }^{50,79}$ were developed, using DMSO as a solvent. (Scheme 4)

Syntheses of other ethers of HMF also were studied. Bredereck ${ }^{80}$ obtained 5(triphenylmethoxy)methylfurfural $\mathbf{8}$ in the course of the reaction of HMF with trityl chloride in pyridine. The acid-catalysed reaction of HMF with simple alcohols led to corresponding ethers, ${ }^{17,81}$ the reaction with ethyleneglycol was catalysed by pyridinium hydrochloride. ${ }^{82}$ (Scheme 4)

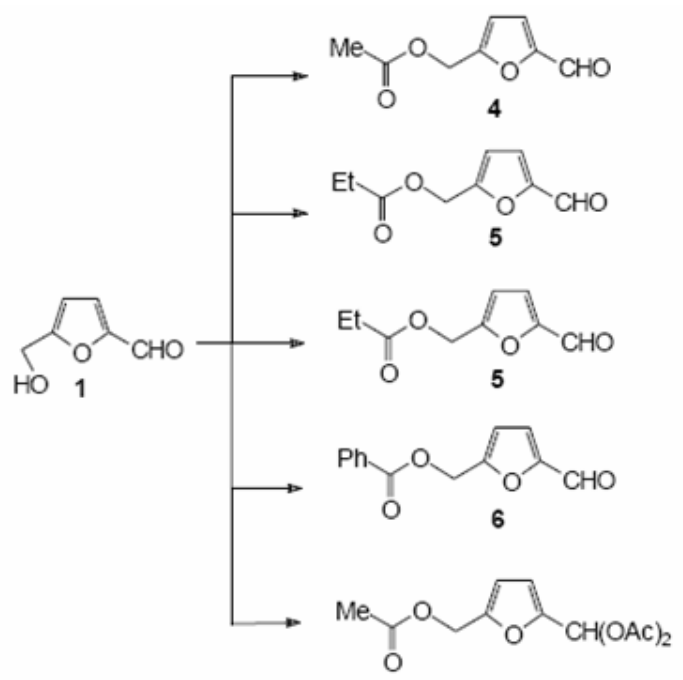

\section{Scheme 3}

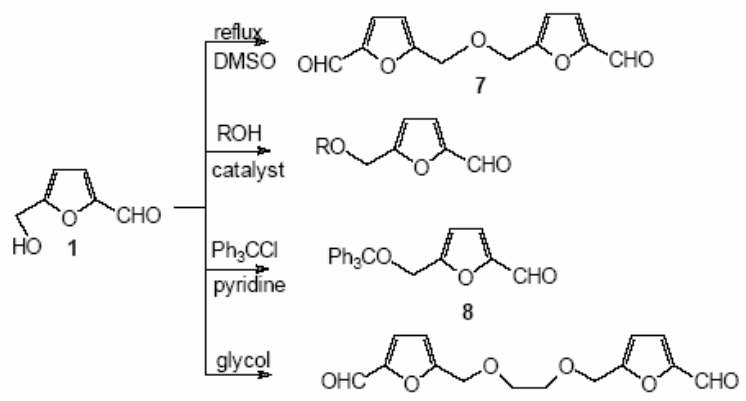

\section{Scheme 4}


Some attempts were undertaken to synthesise monosaccharide ethers of HMF. Cottier ${ }^{83}$ obtained a mixture of $\alpha$-and $\beta$-annomers of the ether resulting from the condensation of HMF with 2,3,4,6-tetra-O-acetyl- $\alpha$-D-glucopyranosyl bromide. Lichtenthaler ${ }^{84,85}$ synthesised several systems of this kind i.e. $\alpha$-D-glycosylmethylfurfurals were obtained in $70 \%$ yield.

Some methods for alcohol group protection were worked out ${ }^{86}$. El-Hajj et al. ${ }^{86}$ performed the reaction of HMF with dihydropyran to obtain 5-(2-tetrahydropyranyl)oxymethylfurfural (9).

Cottier et $a l .{ }^{83,87}$ reported the synthesis of tert-butyldimethylsyliloxymethylfurfural $\mathbf{1 0}$ and benzyloxymethylfurfural. (Scheme 5)

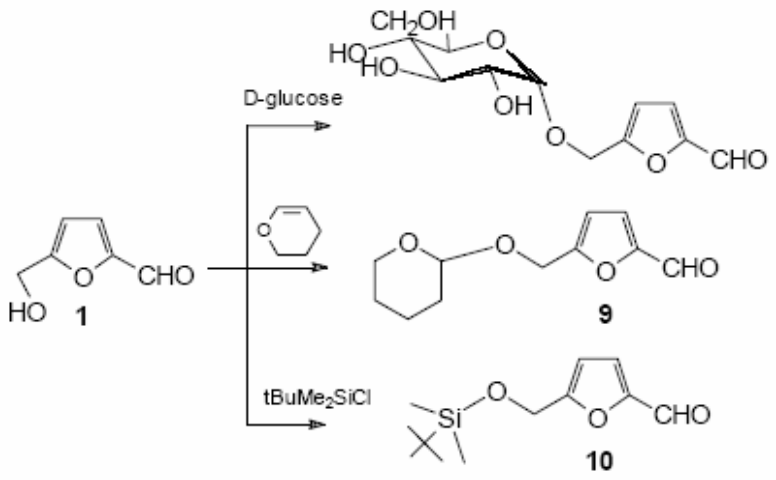

\section{Scheme 5}

\subsubsection{The formation of halides}

The hydroxyl group in HMF undergoes halogen substitution very easily. Reichstein et al. obtained 5-chloromethylfurfural 11 from the reaction of ethereal hydrogen chloride with HMF. Similarly, 5-bromomethylfurfural $\mathbf{1 2}^{12,88}$ was synthesised in the reaction with ethereal hydrogen bromide. 5-Halomethylfurfurals were also obtained directly from D-fructose, ${ }^{9-11,13,89}$ sucrose or from cellulose. ${ }^{10,93}$ Cazalda $^{94}$ synthesised 5-chloromethylfurfural in the reaction of HMF with triphenylphosphine in carbon tetrachloride. (Scheme 6)

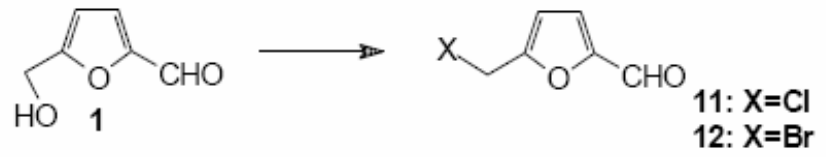

\section{Scheme 6}

Generally a hydroxyl group in primary alcohols is not very reactive towards halogen substitution. In the case of HMF, the reactivity of the hydroxyl group is attributed to the electronwithdrawing character of the furan ring:

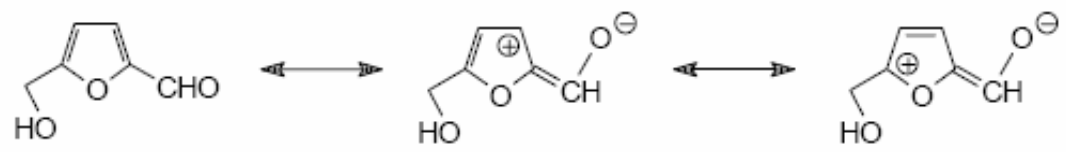

It has been suggested that the transition state is stabilised by simultaneous overlap of the nucleophile with the central carbon atom and the carbon atom at the 5 position of furan ring:<smiles>[Y]C(=O)c1ccc([O-])o1</smiles> 
5-Halomethylfurfurals are extremely reactive, which makes them useful for the synthesis of HMF derivatives. 5-Chloro-and 5-bromomethylfurfural both undergo hydrolysis quantitatively to HMF in hot water. ${ }^{95}$ Both derivatives react also with methanol and ethanol in the presence of barium or calcium carbonates to form corresponding 5-methoxymethylfurfural $\mathbf{1 3}^{12,96}$ and 5ethoxymethylfurfural $\mathbf{1 4} .^{12,89}$ It is intriguing that 5-bromomethylfurfural reacts with sodium cyanide in ethanol to give 5-ethoxymethylfurfural ${ }^{96}$ instead of the expected nitrile. (Scheme 7) 5Chloromethylfurfural undergoes the Friedel-Crafts reaction with benzene and toluene in the presence of aluminium chloride ${ }^{11}$ to give 5-benzylfurfural 15 and p-tolylmethylfurfural 16. 5Methylfurfural 17 was obtained from both the chloro and bromo derivative, when the reaction was catalysed by tin (II) chloride ${ }^{10}$ or by zinc powder and acetic acid. ${ }^{13}$

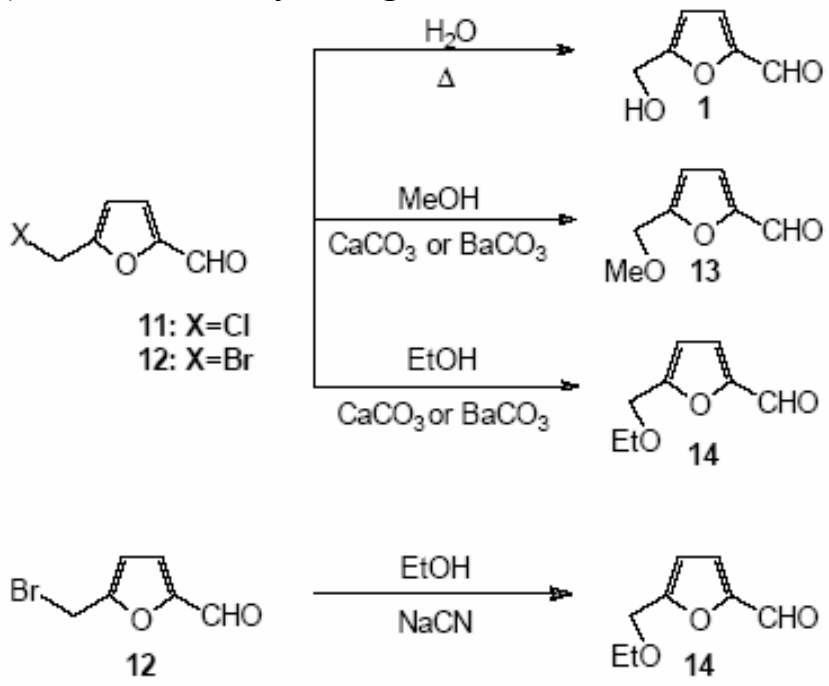

\section{Scheme 7}

Cottier and Descotes ${ }^{83}$ have developed a method of the synthesis of 5-(ortho- and paramethylbenzyl)-furfural in 68\% yield, employing Montmorillonite $\mathrm{K} 10$ as a catalyst. Halomethylfurfurals undergo also the Wurtz-Fittig reaction ${ }^{10,88}$ to give 2,2'-difurylethane-5,5'dicarbaldehyde 18 (Scheme 8)

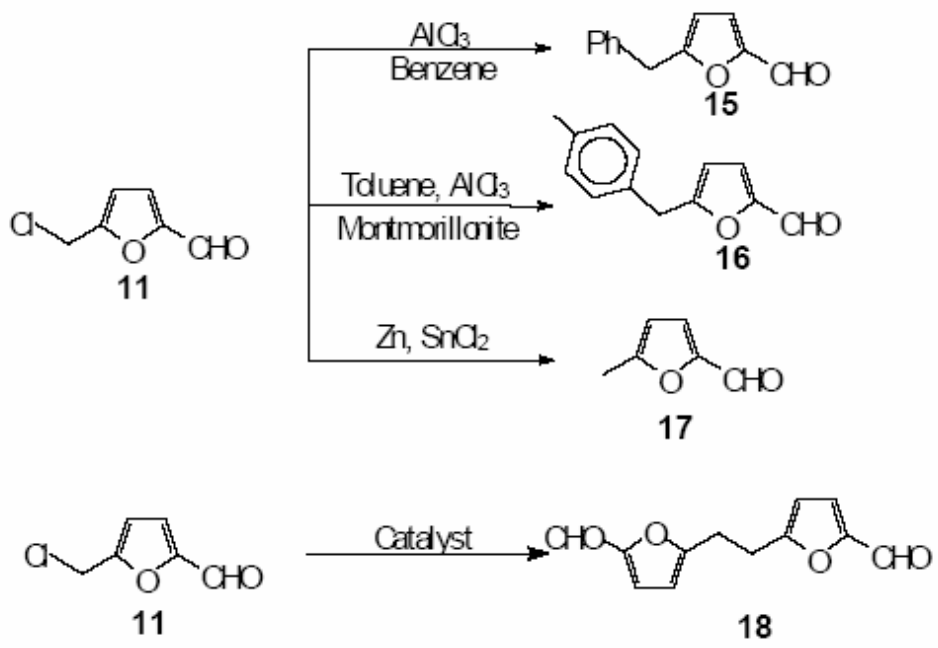

\section{Scheme 8}




\section{III.1.4. Oxidation}

Several authors have described the oxidation of HMF to 2,5-furandicarbaldehyde 19. Reijendam et $a l .{ }^{97}$ reported that the reaction of HMF with lead tetracetate in pyridine gave the dialdehyde in $37 \%$ yield. Morikawa ${ }^{26,98,99}$ oxidised HMF with a variety of oxidants, for example chromium trioxide in pyridine, acetic anhydride in DMSO (Swern oxidation). El-Hajj et al. ${ }^{86}$ performed the oxidation of HMF with barium manganate which gave the dialdehyde 19 in a fair yield. Cottier et al. ${ }^{100}$ used barium manganate under ultrasonic irradiation in a heterogeneous mixture of solid barium manganate and HMF adsorbed on aluminium oxide. The reaction which was carried out in 1,2-dichloroethane afforded the dialdehyde 19 in $25 \%$ yield. (Scheme 9)

The same authors ${ }^{100}$ have tested the modification of Adams' procedure of the oxidation with pyridinium chlorochromate (PCC). They oxidised HMF in a mixture consisting of HMF adsorbed on aluminium oxide and ground together with PCC under ultrasonic irradiation to achieve a dialdehyde of $58 \%$ yield.

Cottier et al. ${ }^{101}$ performed the oxidation of 5-hydroxymethylfurfural with DMSO-potassium dichromate oxidative complex, when ultrasonic irradiation was applied the dialdehyde 19 was obtained in $75 \%$ yield. They utilised also trimethylammonium chlorochomate (TMACC) ${ }^{101}$ for the oxidation of HMF under sonochemical conditions to obtain the dialdehyde in $72 \%$ yield.

Van Bekkum ${ }^{102}$ and Vinke ${ }^{103}$ have developed methods of the selective oxidation of a hydroxymethyl group with noble metal catalysts such as platinum, palladium or ruthenium, that gave excellent yields and selectivities.

Cottier et $a l .{ }^{104}$ reported the oxidation of HMF with various 4-substituted 2,2,6,6tetramethylpiperidine-1-oxide (TEMPO) free radicals and supporting co-oxidants. They tested a variety of co-oxidants such as calcium hypochlorite, sodium hypochlorite-potassium bromide, copper (I) chloride-oxygen pair, p-toluenesulfonic acid, iodine in alkaline conditions or the electrochemically generated $\mathrm{Br}$ radical. Yields varied from $20 \%$ to $80 \%$ depending on the nature of 4-substituent and of the co-oxidant. The best results were obtained using 4-benzoyloxyTEMPO with calcium hypochlorite (yield - 75\%) and 4-acetamido-TEMPO with ptoluenesulfonic acid (yield - 81\%). (Scheme 9)

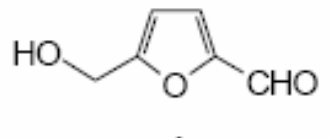

1

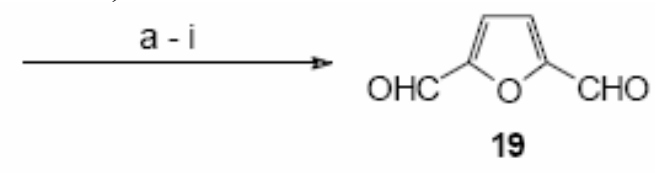

a) $\mathrm{Pb}(\mathrm{OAC})_{4}$, pyridine

b) $\mathrm{CrO}_{3}$, pyridine

c) $\mathrm{AC}_{2} \mathrm{O}$

d) $\mathrm{N}_{2} \mathrm{O}_{4}$, DMSO

e) Pt, Pd or $\mathrm{Ru} / \mathrm{NaOH}$ f) $\mathrm{BaMnO}_{4}, \Delta$ or (((

g) $\mathrm{PCC}, \mathrm{Al}_{2} \mathrm{O}_{3}$

h) TMACC, $\mathrm{Al}_{2} \mathrm{O}_{3}$

i) $\mathrm{K}_{2} \mathrm{Cr}_{2} \mathrm{O}_{7}-\mathrm{DMSO}$

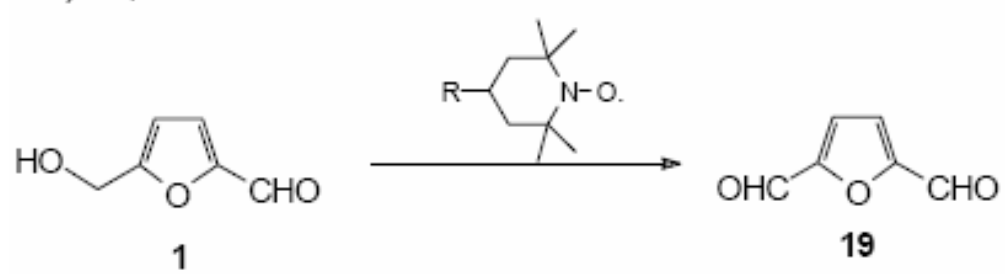

Scheme 9 
Cottier et ll $^{87}$ has reported also the indirect oxidation of HMF to the dialdehyde 19. HMF was converted into its silyl ethers (5-tert-butyldimethylsyliloxymethylfurfural $\mathbf{1 0}$ and 5trimethylsilyloxymethylfurfural 10a) and the oxidation was promoted by $N$-bromosuccinimide (NBS) in the presence of azoisobutyronitrile (AIBN). A study of the influence of solvent established that the best solvents for this purpose are 1,2-dichloroethane, carbon tetrachloride or dodecane, with the yields of dialdehyde in 76-91\% range. (Scheme 10)

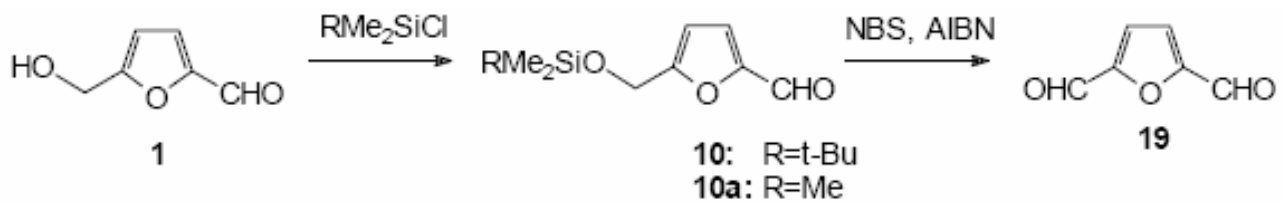

Scheme 10

\subsection{Reactions of the formyl group}

\subsubsection{Reduction}

2,5-Bis-(hydroxymethyl)furan $\mathbf{2 0}$ is a compound with a great field of application in the preparation of resins, polymers and artificial fibres. ${ }^{105}$ It has been synthesised by the reduction of formyl group in HMF catalysed by nickel, copper chromite, platinum oxide, cobalt oxide or molybdenum oxide, and also sodium amalgam. ${ }^{4}$ (Scheme 11)

A catalytic hydrogenation of HMF in an aqueous medium in the presence of nickel, copper, platinum, palladium or ruthenium catalysts was investigated. ${ }^{106}$ The copper or platinumcatalysed reaction resulted in 2,5-bis-(hydroxymethyl)furan as a predominant product, while the application of nickel or palladium caused the hydrogenation of the furan ring. In this case mainly 2,5-bis-(hydroxymethyl)tetrahydrofuran 21 was obtained. ${ }^{106}$ (Scheme 11)

There are various reports of studies of reduction with sodium borohydride. ${ }^{17,78,107}$ Reichstein ${ }^{13}$ reduced HMF with hydrazine or sodium ethanolate to give 5-hydroxymethyl-2methylfuran (22), and 2,5-bis-(hydroxymethyl)furan, respectively. Reynolds ${ }^{108}$ performed the reductive amination of HMF to obtain 5-hydroxymethyl-2-tetrahydrofurfurylamine $\mathbf{2 3}$ and its $\mathrm{N}$ substituted derivatives. (Scheme 11)

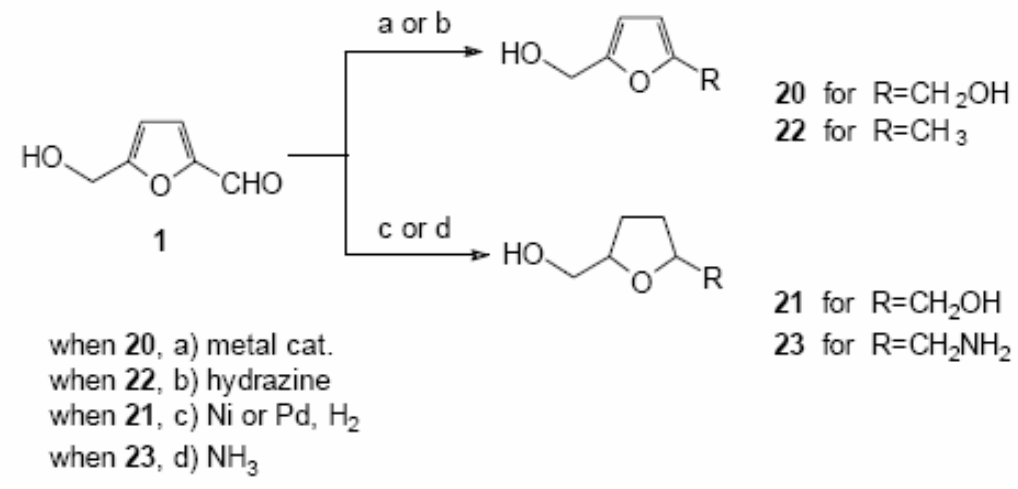

Scheme 11

\subsubsection{Condensation reactions}

In contrast to furfural, which undergoes the addition of ammonia ${ }^{109}, \mathrm{HMF}$ is decomposed under similar conditions and the formation of polymeric products is observed ${ }^{6}$. However, HMF does 
react with derivatives of ammonia to form compounds such as oximes (24), ${ }^{8}$ phenylhydrazone $\mathbf{2 5},{ }^{8,75,110}$ p-nitrophenylhydrazone 26, ${ }^{111}$ semioxamazone $\mathbf{2 7},{ }^{111}$ semicarbazone $28^{112}$ and azine $\mathbf{2 9}^{10}$ (Scheme 12). HMF reacts with aromatic amines to form Schiff bases. Cooper ${ }^{95}$ has reported the reaction of HMF with aniline and $\beta$-naphthylamine, and Kalinich ${ }^{113}$ has observed that with Nmethylaniline in ethanol leads to formation of the 5-hydroxymethylfurfurylidene-N-phenyl-Nmethylimminium cation 30. (Scheme 13)

The condensation of HMF with urea lead to 5-hydroxymethylfurfurylidene-bis-urea 31, a similar reaction with acetamide and benzamide affords 5-hydroxymethylfurfurylidene-bisacetamide 32 and bis-benzamide 33 respectively. ${ }^{16}$ When HMF is treated with methyl aminoformate, dimethyl-5-hydroxymethylfurfurylidene-bis-(N-aminoformate) $\mathbf{3 4}$ is formed. (Scheme 14)
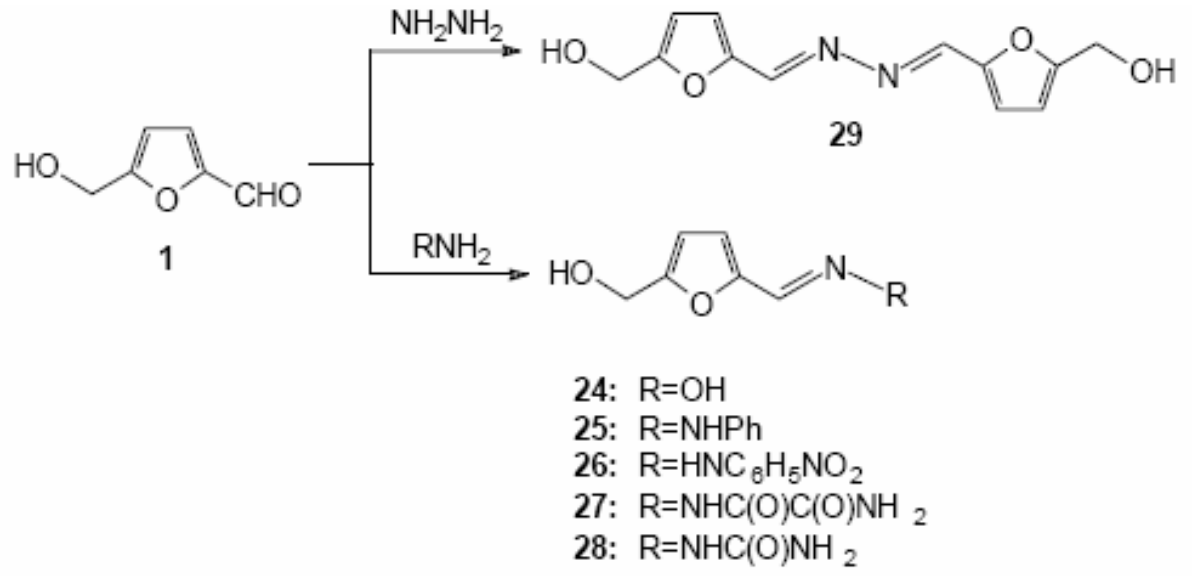

\section{Scheme 12}

Blanksma ${ }^{114}$ has described the reaction of HMF with citric acid trihydrazide, which gives citric acid tris-[N-(5-hydroxymethyl)furfurylidene] hydrazide 35.

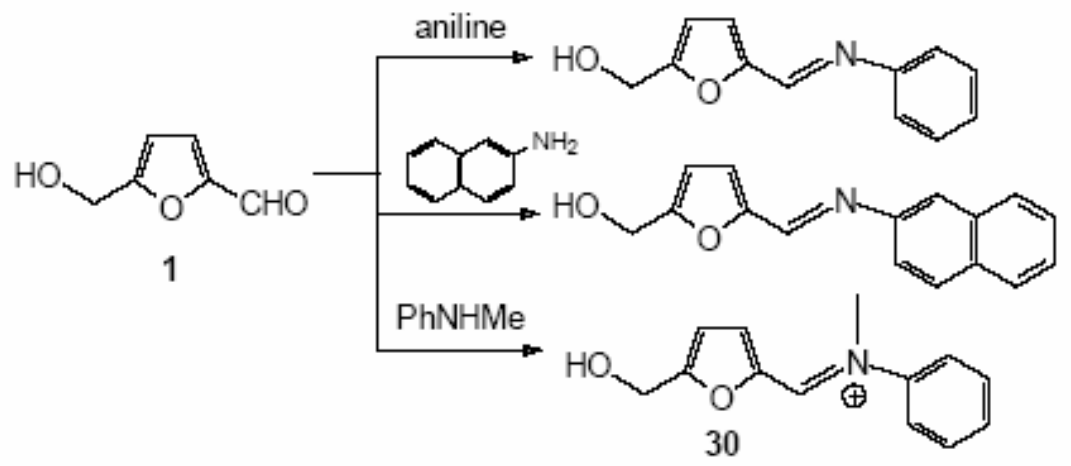

\section{Scheme 13}

The reaction of HMF with 2-aminothiophenol ${ }^{115}$ is noteworthy as it leads to the formation of a new heterocyclic system - 2-(5-hydroxymethylfurfuryl)-benzothiazole 36. (Scheme 14) 


\section{Scheme 14}
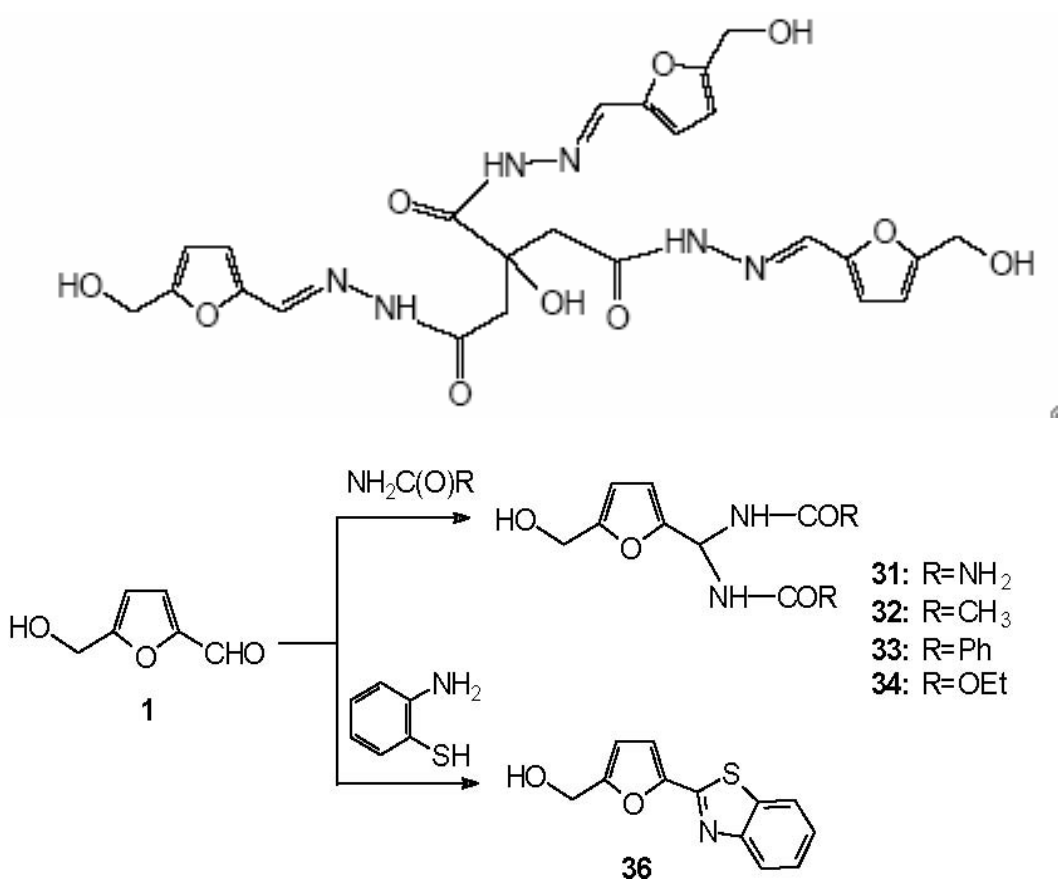

HMF undergoes reaction with compounds bearing an active methylene group. Karashima ${ }^{16}$ has carried out the Perkin condensation to afford 5-acetoxymethyl-furfurylideneacetic acid $\mathbf{3 7}$. HMF reacts with malonic esters, ${ }^{12}$ hydantoin ${ }^{116}$ or with acrylonitrile. ${ }^{117}$ HMF reacts with malonic acid in pyridine in the presence of a catalytic amount of piperidine to yield 5-hydroxymethylfurfurylideneacetic acid 37a, ${ }^{118}$ subsequent electrochemical oxidation at a nickel oxidehydroxide anode affords 5-carboxy-2-furfurylideneacetic acid $\mathbf{3 7 b}$. HMF also undergoes the Horner-Wittig reaction ${ }^{120}$ with ethyl diethylphosphonoacetate to give ethyl 5hydroxymethylfurfurylideneacetate 38. (Scheme 15)

The Claisen-Schmidt condensation of HMF has also been carried out with acetone, ${ }^{12}$ with anthrone, ${ }^{2}$ with barbituric acid, ${ }^{119}$ with acetophenone ${ }^{118}$ to obtain 5-hydroxymethylfurfurylideneacetophenone. This compound was subsequently oxidised to 5-carboxy ${ }^{18}$ and 5formy $1^{100,104}$ derivatives. $\alpha, \beta$-Unsaturated ketones, formed by Claisen-Schmidt condensation reacted with $\mathrm{N}$-substituted hydrazines and guanidine ${ }^{83}$ to yield furan substituted pyrazoles and pyrimidines. (Scheme 16)

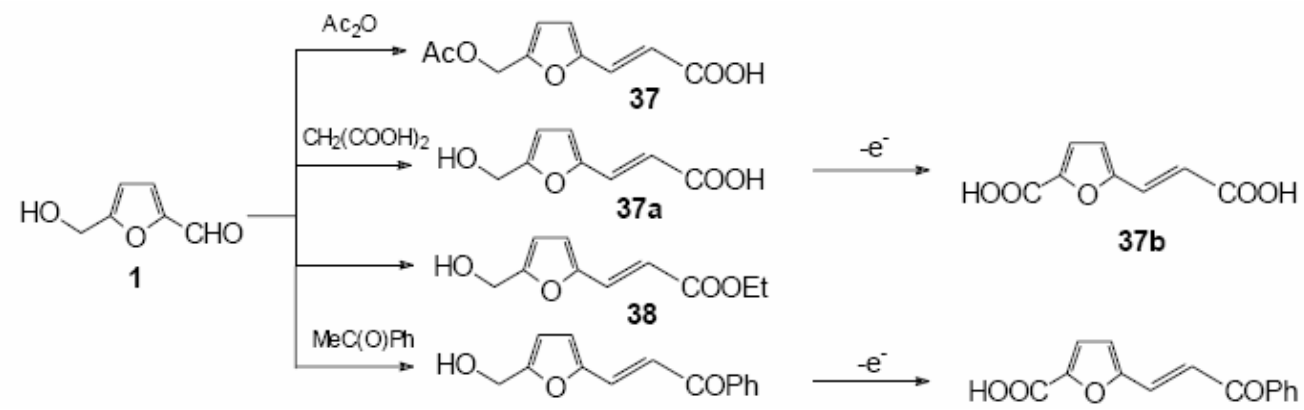

Scheme 15 
HMF also reacts with alcohols to give acetals. The reaction with 2,2-dimethyl-1,3propanediol $^{121}$ gave a cyclic acetal, which is utilised in the preparation of compounds for ionophoresis. Acetals were also obtained by the reaction with ethylene glycol and methanol. ${ }^{82}$

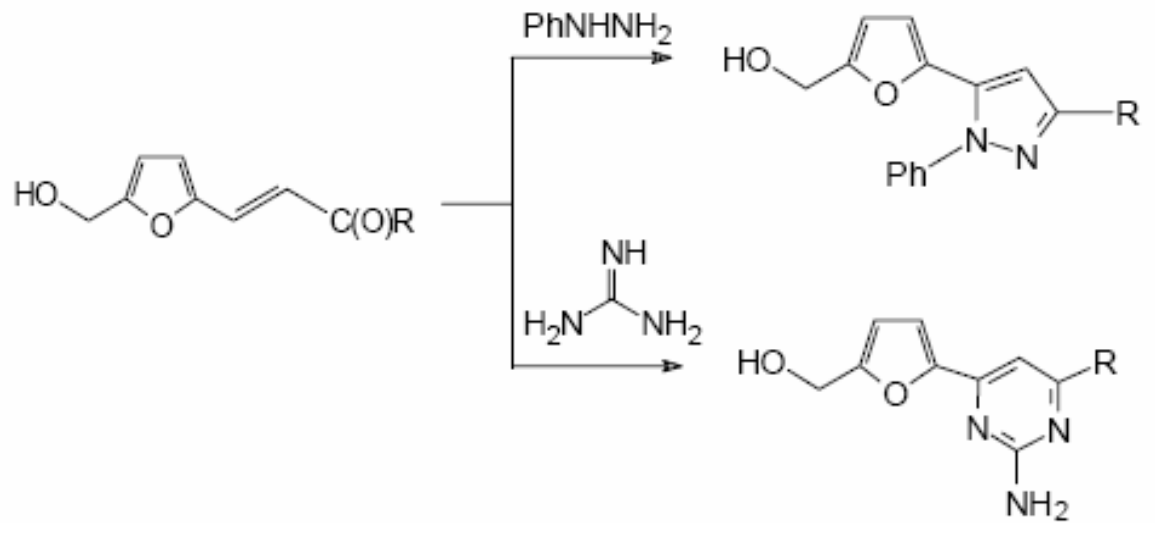

\section{Scheme 16}

\subsubsection{Oxidation reactions}

It is well known that the formyl group may easily be converted into a carboxylic group - the formyl group on HMF is no exception. The oxidation of the formyl group can be selective leaving the hydroxyl group intact - 5-hydroxymethyl-2-furancarboxylic acid $\mathbf{3 9}$ is then the exclusive product. Reichstein, ${ }^{14}$ oxidised HMF with silver oxide to achieve this conversion. A mixture of silver and copper (II) oxides, ${ }^{122}$ and oxygen in the presence of noble metals as catalysts have also been used for the selective oxidation of HMF. ${ }^{102,103}$

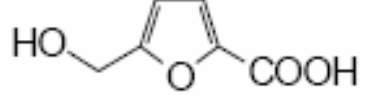

39

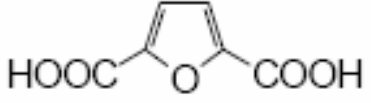

40

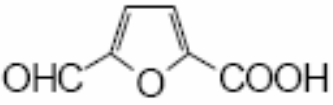

41

The oxidation of HMF to 2,5-furandicarboxylic acid $\mathbf{4 0}$ has been described by Van Bekkum $^{102}$ and Vinke ${ }^{103}$ who used oxygen and noble metals as catalysts. Morikawa ${ }^{123}$ used nitrogen oxides and nitric acid to obtain the diacid $\mathbf{4 0}$ in high yield. El-Hajj ${ }^{44}$ and Cottier ${ }^{100}$ have oxidised HMF with nitric acid. El-Hajj ${ }^{44}$ claimed this reaction to be selective i.e. that the diacid 40 was the exclusive product, while Cottier's and co-workers' found that the oxidation of HMF with nitric acid led to the diacid $\mathbf{4 0}$ and 5-formyl-2-furancarboxylic acid $\mathbf{4 1}$, which was found to be resistant to oxidation under these conditions. The ratio of these two products depended on the reaction conditions. They ${ }^{100}$ tested aqueous as well as mixed solvents (such as DMSO or acetic acid), and they studied the chemical behaviour with and without the catalyst and the influence of ultrasound. In each case, the formation of both products was detected. According to Cottier's and co-workers' results ${ }^{100}$ and unpublished studies of the author of this article, the formylacid $\mathbf{4 1}$ is so resistant to oxidation in acidic conditions owing to the protonation of the carboxylic group leading to, the stabilisation of the formyl group. 

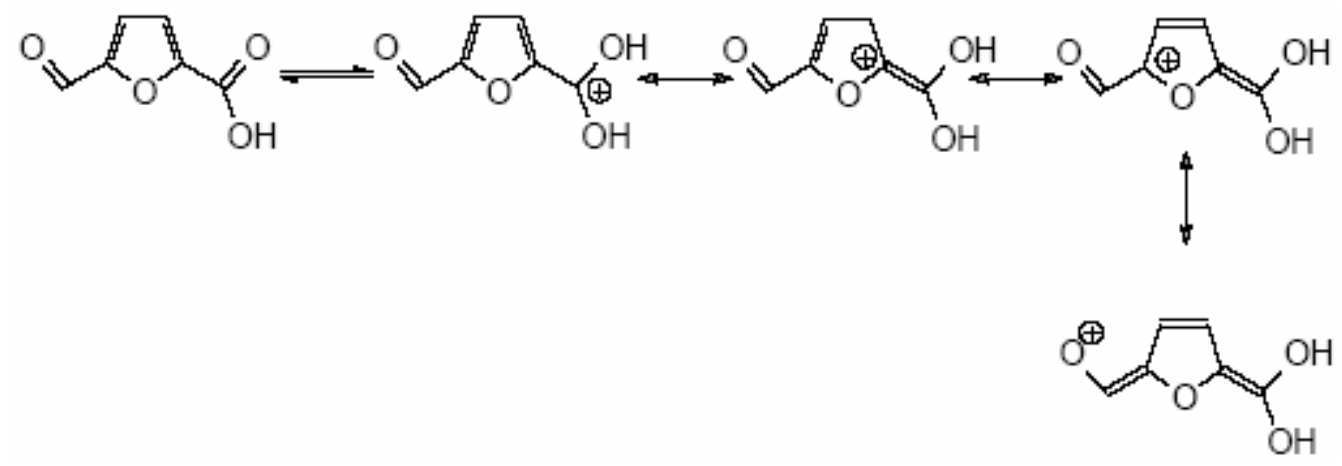

HMF undergoes the Canizzaro reaction to form of 2,5-furandicarboxylic acid and 2,5-bis(hydroxymethyl)furan. ${ }^{124}$

Lillwitz ${ }^{125}$ performed the decarbonylation of HMF in the presence of calcium acetate and other catalysts to give furfuryl alcohol.

\subsection{Reactions of the furan ring}

Cleavage of the furan ring occurs in acidic medium ${ }^{126}$ to give levulinic acid, formic acid and various polymeric substances. Recently, Horvat ${ }^{127}$ has proposed the mechanism of HMF degradation. The reaction proceeds via two possible routes (path ' $a$ ' and 'b'), which depend on the position of water addition $(2,3$ or 4,5$)$. (Scheme 17)

The reaction via mechanism 'a' leads to the formation of 2,5-dioxo-3-hexenal, which undergoes the decomposition to levulinic and formic acids. According to the author of this review, the intermediate A explains well the liberation of formic acid. Reaction through the path ' $b$ ' results in the formation of polymers.

The reduction of HMF on Raney nickel results in the formation of 2,5-bis-(hydroxymethyl) tetrahydrofuran. ${ }^{128}$ The catalytic hydrogenation of $\mathrm{HMF}^{106}$ in acidic conditions in the presence of platinum or ruthenium leads to 1-hydroxy-2,5-hexenedione $\mathbf{4 2}$ and subsequently to 1,2,5hexenetriol 43 (Scheme 18).
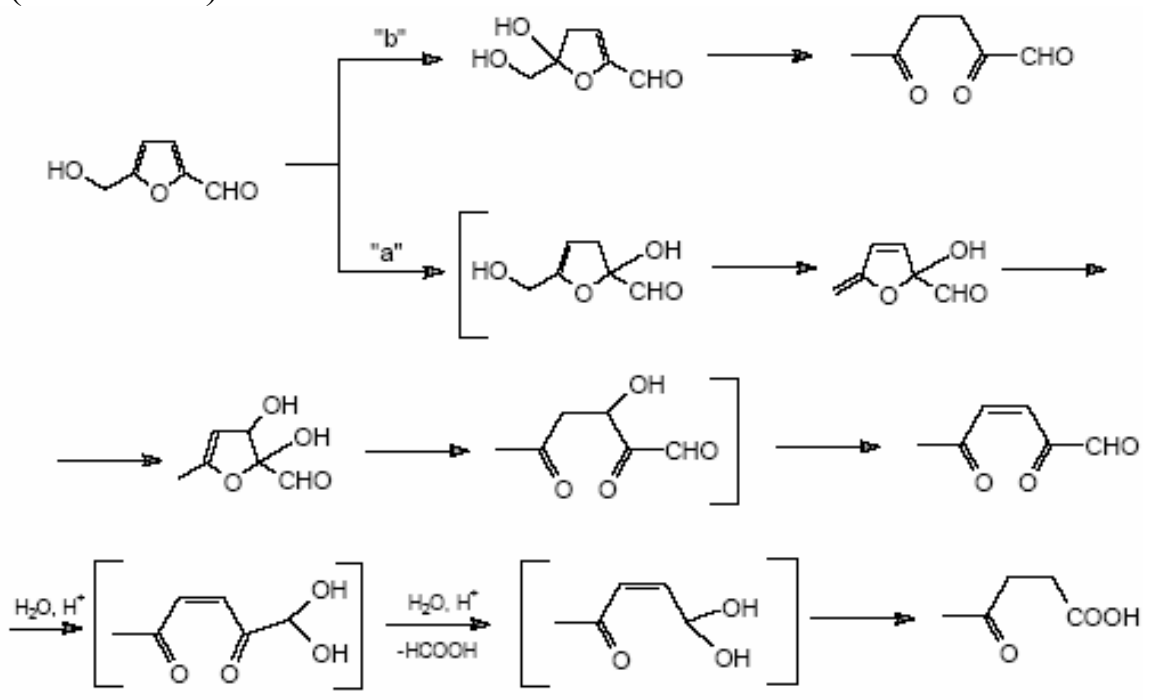

\section{Scheme 17}


Photochemical oxidation of HMF in alcohol results first in the formation of endoperoxides. The attack of an alcohol molecule on a formyl group or on a carbon atom ' 5 ' in the furan ring leads to the formation of hydroxy-or alcoxybutenolide. ${ }^{82}$ Hydroxybutenolides are converted into butenolide- $\gamma$-ketoacrylic ester, $\gamma$-hydroxy-acrylic esters and saturated $\gamma$-hydroxy-esters. ${ }^{82,83}$ (Scheme 19)

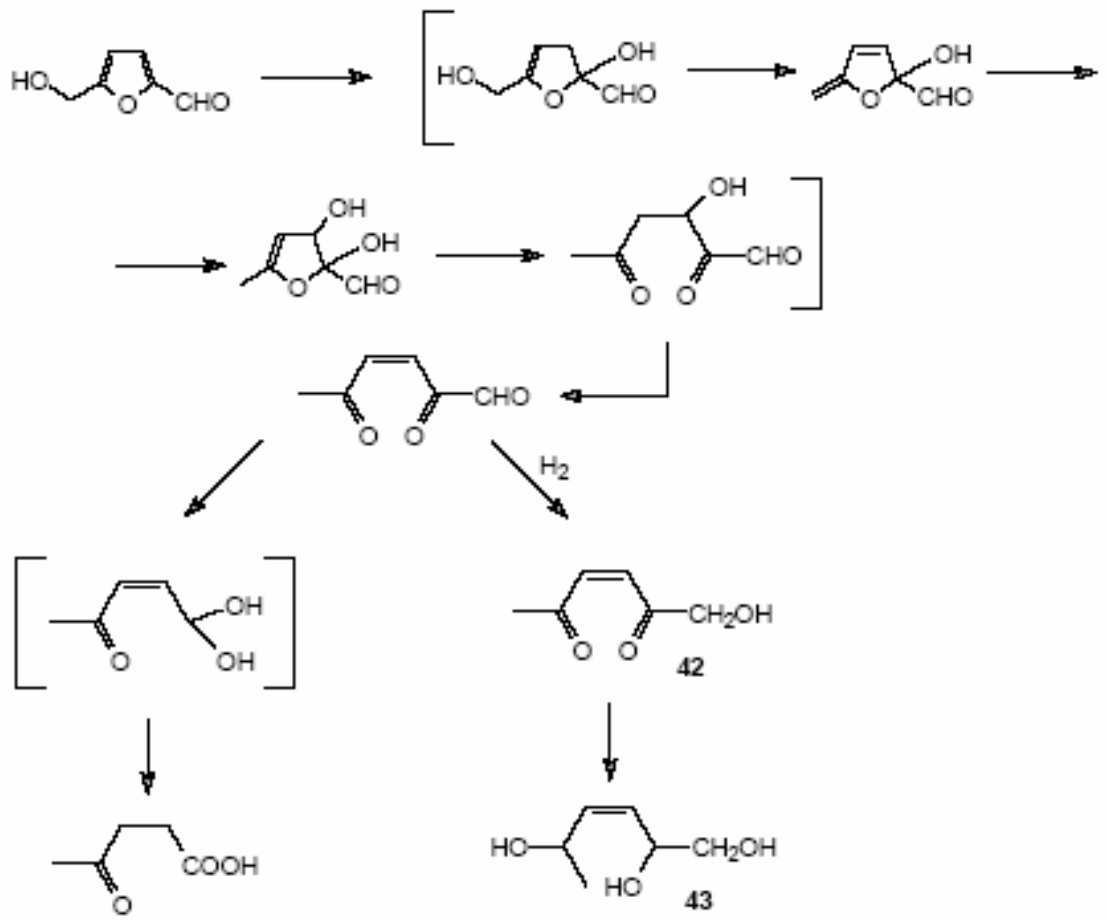

\section{Scheme 18}

\subsection{Polymerisation of HMF}

HMF reacts with phenols giving products of condensation or resins depending on $\mathrm{pH}$. These resins react with hexamethylenetetramine (aminoform) with the formation of adhesives utilised as plasticizers. ${ }^{129} 5$-Hydroxymethylfurfural forms thermoresistant resins in the reaction with $\mathrm{p}$ toluenesulfonamide or butanone. ${ }^{129,130}$ The reaction of HMF with polyisocyanates ${ }^{131}$ gives polyurethanes, which are utilised to the production of infusible and insoluble fibres. According to Gandini, ${ }^{19}$ when starch is used as a stabiliser in a phenolate resin synthesis, there is the evidence for HMF formation. The latter reacts subsequently with phenol through its formyl and hydroxyl groups. HMF is also a precursor of a bifunctional furan monomer utilised in the preparation of thermoplastics. 


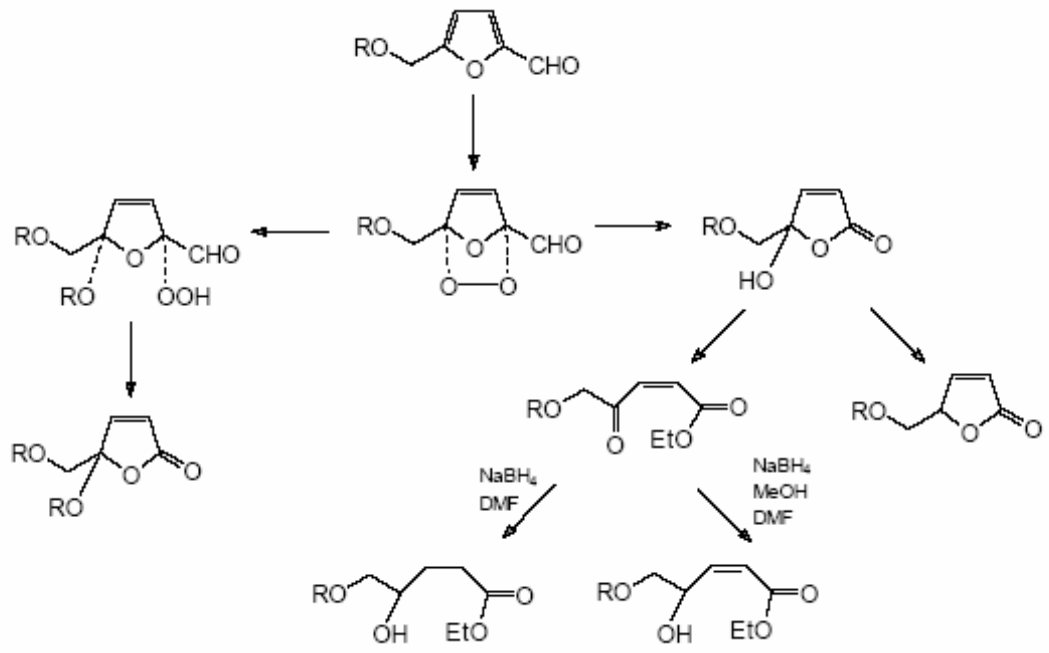

\section{Scheme 19}

\subsection{Electrochemical conversions of HMF}

The chemistry of HMF, is well documented, however the electrochemistry of this compound is scarcely described. Several articles were published presenting some of electrochemical conversions of HMF. Kawana ${ }^{132}$ carried out the electrolysis of HMF and its derivatives at a platinum anode in methanol as solvent with lithium perchlorate as a supporting electrolyte. The anodic electrolysis of 5-acetoxymethylfurfural resulted in methyl (Z)-5-acetoxy-4,4-dimethoxy2-pentenoate 44, the same reaction performed with 5-acetoxymethylfurfuryl alcohol also gave the ester 44 . Yields were 81 and $91 \%$ respectively. (Scheme 20)

2-(1-Acetoxyalkyl)-5-(ethoxymethyl)furan $\mathbf{4 5}$ was oxidised under the same conditions to give methyl(Z)-acetoxy-5-alkyl-4,4-dimethoxy-2-pentenoate $\mathbf{4 6}$ in $79-93 \%$ yield. The electrooxidation of HMF yielded methyl malonate, and the reaction of 2-(1-hydroxyethyl)-5(ethoxymethyl)furan $\mathbf{4 7}$ resulted in methyl succinate. (Scheme 20)

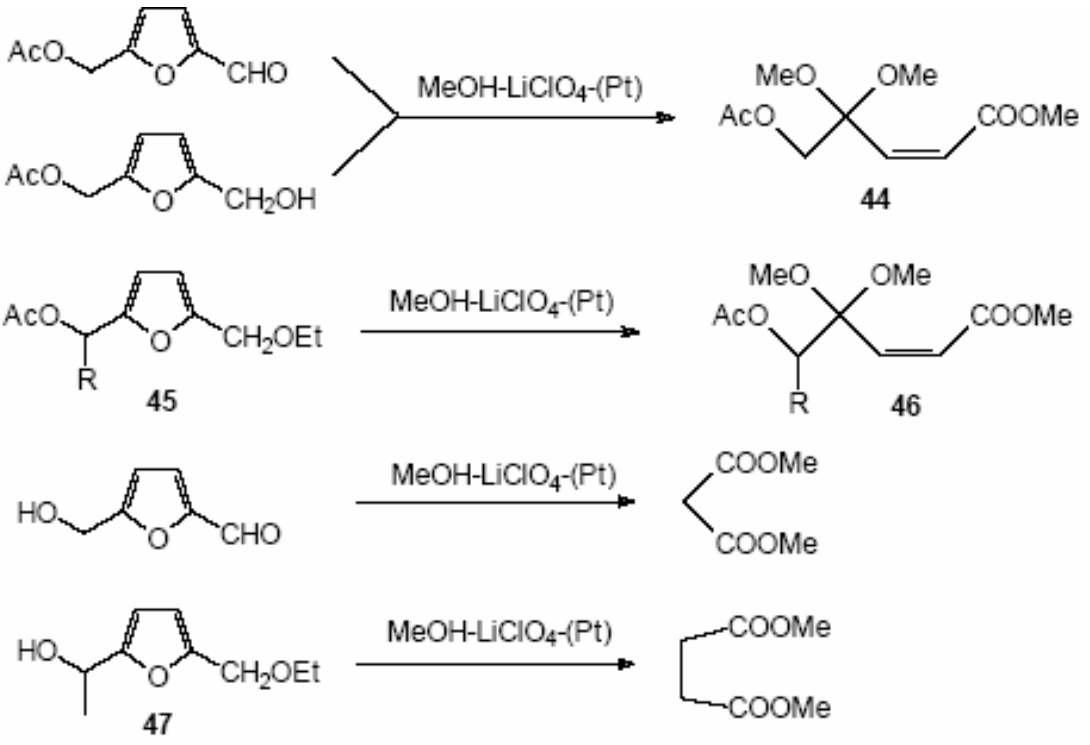

Scheme 20 
El-Hajj ${ }^{133}$ performed the electrolysis of HMF at a platinum anode in methanolic solution of tetrabutylammonium perchlorate. The electrooxidation resulted in six products, 2,5-dimethoxy2-dimethoxymethyl-5-hydroxymethyl-2,5-dihydrofuran $\mathbf{4 8}$ was isolated in $11 \%$ yield as a predominant product.

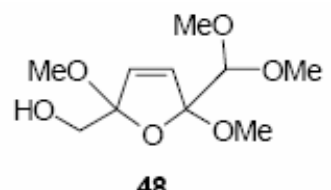

Grabowski et al. ${ }^{134,135}$ oxidised HMF at a nickel oxide-hydroxide electrode in alkaline aqueous solution of sodium hydroxide. The reaction was carried out in a divided cell, and resulted in formation of 2,5-furandicarboxylic acid $\mathbf{4 0}$ in $71 \%$ yield, as the exclusive product.

Cottier et al. ${ }^{136}$ performed the electrochemical oxidation of HMF resulting in 2,5furandicarbaldehyde 19. The reaction was carried out in a divided cell at a platinum anode in a biphasic (water-dichloromethane) system. Various slightly basic salts such as sodium acetate, sodium hydrogen carbonate, or mono- and disodium phosphates were tested as a supporting electrolyte. Yields varied from $32 \%$ to $40 \%$, with $100 \%$ selectivity, as the dialdehyde 19 was an exclusive product. The organic layer of the biphasic system acted as a trap to capture the dialdehyde $\mathbf{1 9}$ as it was formed protecting it from subsequent oxidation to the diacid. (Scheme 21)

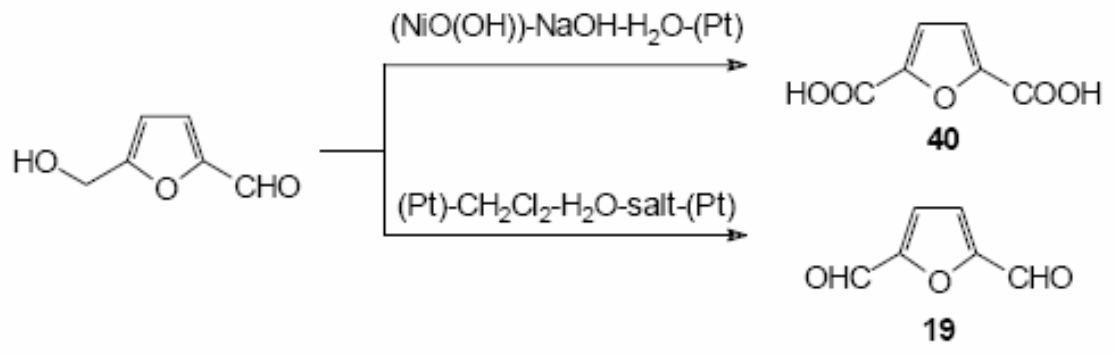

Scheme 21

\section{PART B. 2,5-FURANDICARBALDEHYDE (FDC)}

\section{The synthesis of 2,5-furandicarbaldehyde (FDC)}

2,5-Furandicarbaldehyde 19, known by its acronym FDC is one of the most important furan derivatives. There are numerous syntheses of this compound, which may be divided into two groups: methods starting with HMF as a substrate, and those, which utilise other furan derivatives as starting materials.

Pastour and Plantard ${ }^{137}$ developed a method for the preparation of FDC (in $36 \%$ yield) from furfural via its diethyl acetal, which was reacted subsequently with butyllithium and dimethylformamide. ${ }^{138}$ 2,5-Furandiarbonitrile $\mathbf{4 9}$ may be reduced with di-(iso-butyl)aluminium hydride in benzene, to FDC in $66 \%$ yield. ${ }^{13}$,

Feringa and co-workers ${ }^{140}$ treated lithiated furan with DMF to obtain 19 in $80 \%$ yield. The same authors ${ }^{140}$ converted furfural into its ethylene glycol acetal, which was lithiated with lithium diisopropylamide (LDA) and the organolithium derivative was reacted with DMF to give 
the dialdehyde 19 in $73 \%$ yield. Carpenter and Chadwick ${ }^{141}$ lithiated 1,3-dimethyl-2-(2furyl)imidazoline with butylithium and the resulting lithium derivative was converted into the 5formyl derivative by the reaction with DMF. The subsequent hydrolysis led to the dialdehyde 19. Several methods utilize 2,5-bis-(hydroxymethyl)furan $\mathbf{2 0}$ as a substrate and the dialdehyde is produced by the oxidation of the former. Oxidizing agents used include chromium trioxide in pyridine $^{142}$ (57\% yield of FDC), pyridinium dichromate in dichloromethane ${ }^{64}$ ( $65 \%$ yield). The same type of oxidation was performed by Oleynik et al., ${ }^{143}$ who reported $100 \%$ yield. (Scheme 22)

FDC has also been synthesised by the oxidation of 2,5-bis-(chloromethyl)furan $\mathbf{5 0}^{144,145}$ or 5chloromethylfurfural ${ }^{95,117}$ with nitric acid. Johnson and $\mathrm{Kidd}^{146}$ performed the hydrolysis of 5[(4-dimethylaminophenyl)oximine]methylfurfural to obtain FDC, Stibor et al. $^{147}$ and Tokada ${ }^{148}$ reduced 2,5-furandicarboxylic dichloride 51 with tributyltin hydride to produce FDC in 59\% yield. (Scheme 22)

Cottier et $a l^{87}$ has carried out a radical oxidation of 5-(tertbutyldimethyl)silyloxymethylfurfural 10 and 5-(trimethyl)silyloxymethylfurfural 10a with Nbromosuccinimide in the presence of azoisobutyronitrile (AIBN) to afford FDC in $83 \%$ and $91 \%$ yield respectively.

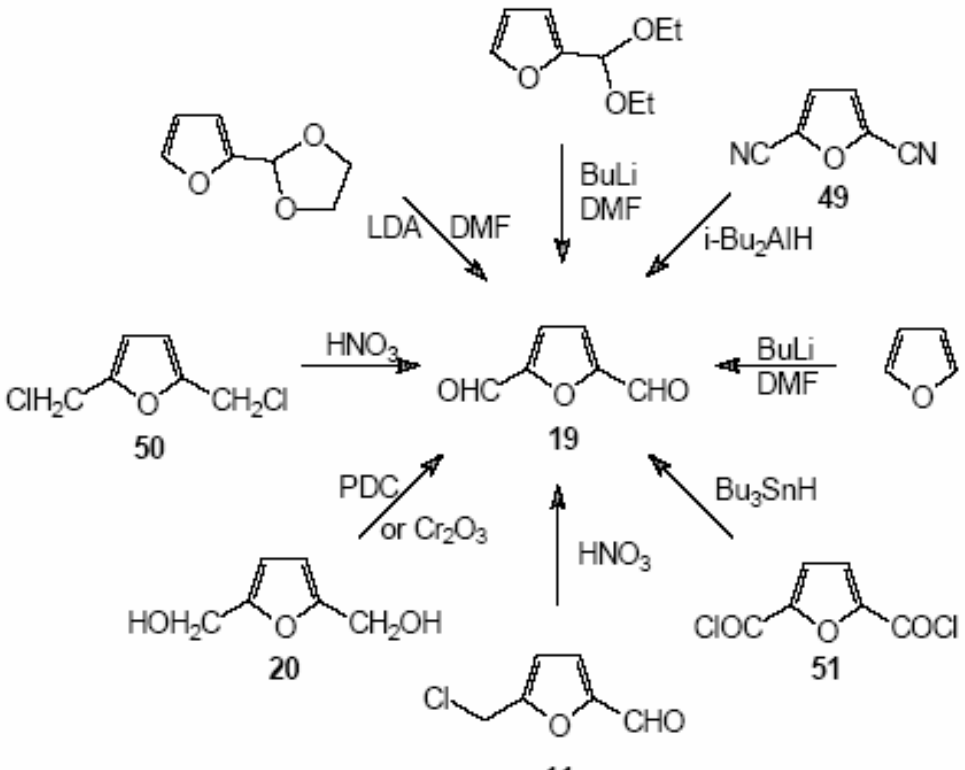

11

\section{Scheme 22}

Van Reijendam ${ }^{97}$ was the firstto oxidize successfully HMF with lead tetraacetate to afford FDC in $37 \%$ yield. Several others have oxidized HMF to FDC, they have utilized: chromium trioxide-pyridine complex ${ }^{123}$ (73\% yield), Ac2O-DMSO (77\% yield), nitrogen dioxide in DMSO (76\% yield), and nitric acid in DMSO (67\% yield), ${ }^{123}$ phosphorus acid-DMSO catalysed by dicyclopentyl-carbodiimide as a water trap (80\% yield), ${ }^{149}$ barium manganate $^{44}$ (93\% yield). Some attempts ${ }^{150}$ have been made to oxidise HMF with potassium permanganate but this synthesis was not valuable as a preparative method due to the lack of the efficiency. Some other oxidizing agents are; vanadium pentoxide and molybdenum trioxide ${ }^{151}$ (60\% yield), pyridinium 
chlorochromate activated by ultrasound ${ }^{100}$ (58\% yield), trimethylammonium chlorochromate ${ }^{101}$ (72\% yield), DMSO-potassium dichromate complex ${ }^{101}$ (75\% yield), TEMPO radicals ${ }^{104}$ (high yields).

\section{The chemistry and applications of 2,5 -furandicarbaldehyde (FDC)}

FDC undergoes all reactions typical for aldehydes. Formation of oximes, has been described by El-Hajj, ${ }^{44}$ addition of aliphatic and aromatic amines ${ }^{152}$ leads to imines. A method for the reduction of dialdehyde 19 to 2,5-bis-(hydroxymethyl)furan $\mathbf{2 0}$ has appeared; ${ }^{153}$ several papers have been devoted to its oxidation to 2,5-furandiarboxylic acid $\mathbf{4 0} ;{ }^{44,95,149,153}$ especially important papers described the catalytic oxidation with noble metals ${ }^{102,103}$.

The most important conversions of FDC are reactions based on the Wittig reaction. ${ }^{152,154,155}$ They are significant from the point of view of organic synthesis - a series of $\alpha, \beta$-unsaturated carbonyl compounds as well as vinyl derivatives have been obtained by the functionalisation of one or both formyl groups. (Scheme 23)

A number of papers ${ }^{155,156}$ have described the synthesis of various ethynyl furan derivatives substituted in positions ' 2 ' and ' 5 '. FDC, according to authors is the best starting material for this purpose.

Numerous examples were quoted in the field of application of FDC. Here we focus on two of them. First is the synthesis of 2-(5-formylfurfuryl)-9,10-phenanthroxazole 52. It was obtained by the condensation of the dialdehyde 19 with 10-amino-9-phenanthrol. ${ }^{159}$ (Scheme 24)

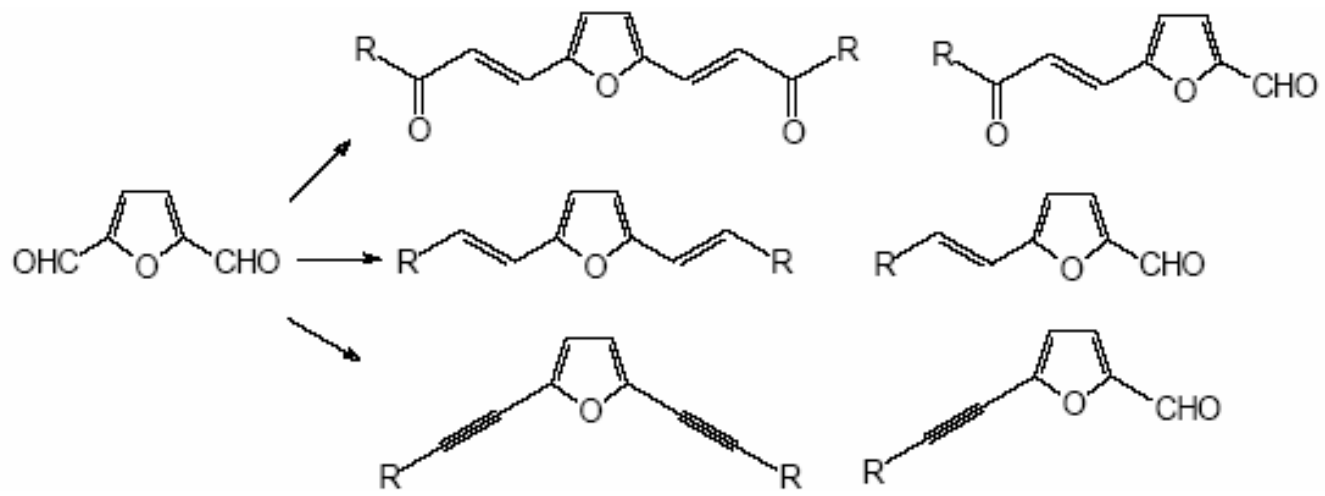

Scheme 23

Daub et al. ${ }^{160}$ synthesised the furylazulene derivative. They converted FDC into 2,5-bis(dicyanovinyl)furan 53 by its condensation with malononitrile. The subsequent [8+2] cycloaddition of the compound $\mathbf{5 3}$ to 8-methoxyheptafulvene 54 resulted in 1,1-dicyano-2-[5(dicyanovinyl)furfuryl]azulene 55. (Scheme 24) 


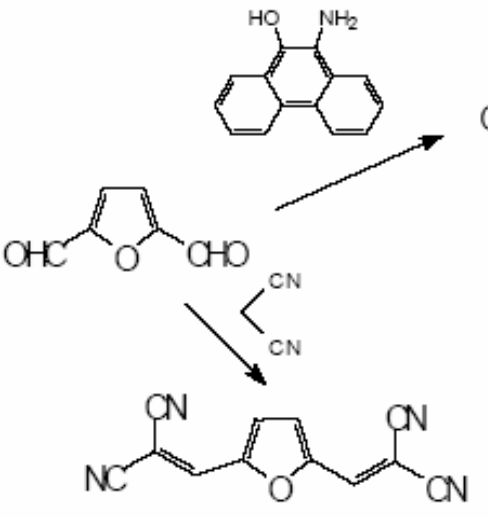

53
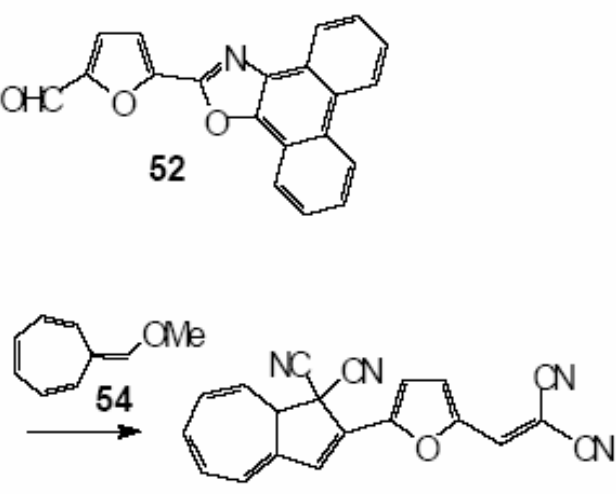

55

\section{Scheme 24}

2,5-Furandicarbaldehyde 19 was utilised in the synthesis of various macrocyclic compounds. The most important are oxo-annulenes. Cresp and Sargent ${ }^{161}$ synthesised 2,5:8,11:14,17-triepoxy [17] annulenone $\mathbf{5 6}$ by the reaction of FDC with carbonyl-di(furan-2,5-diyl)-dimethylene-bistriphenylphosphonium chloride. (Scheme 25)

In the same way, 1,4:7,10:13,16-triepoxy [18] annulene (57) was synthesised from FDC and the appropriate Wittig reagent. ${ }^{162 \mathrm{~b}}$ The reaction of FDC with trimethylene-bis(triphenylphosphonium) bromide resulted in the formation of 1,4:16,13-diepoxy[18]annulene 58. ${ }^{162 \mathrm{a}}$ (Scheme 25)

A very interesting application of FDC was worked out by El-Hajj and co-workers. ${ }^{86}$ They performed the reaction of the dialdehyde 19 with methyl-vinyl ketone to obtain 2,5-bis-(1,4dioxopentyl)furan 59, which was subsequently oxidised to the terfuryl derivative. (Scheme 26)

2,5-Furandicarbaldehyde 19 has also been used in the synthesis of 21-oxoporfirine (60). ${ }^{64,163}$ It was synthesised by the reaction of FDC with tripyrrole derivatives in $22 \%$ yield.

\section{Scheme 25}

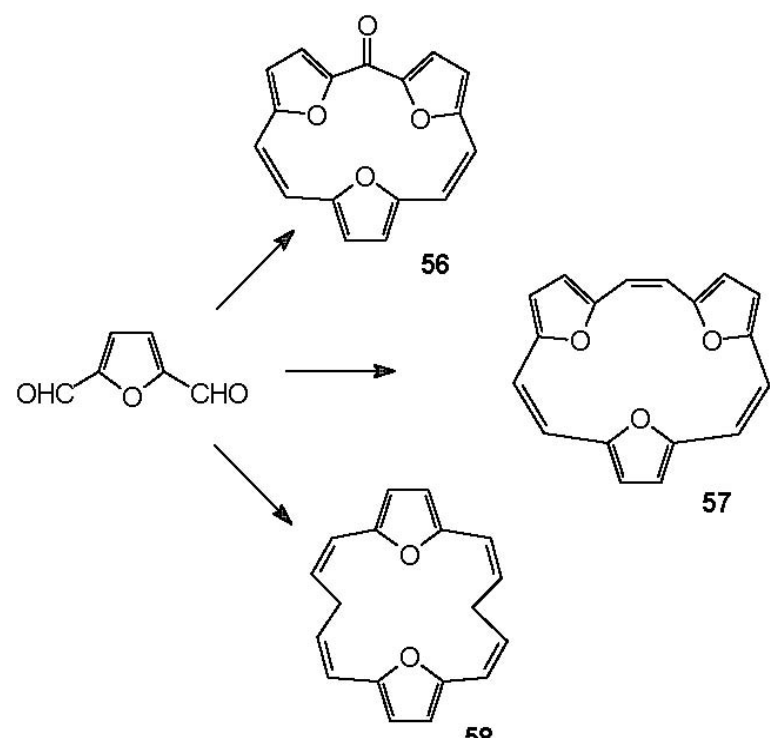




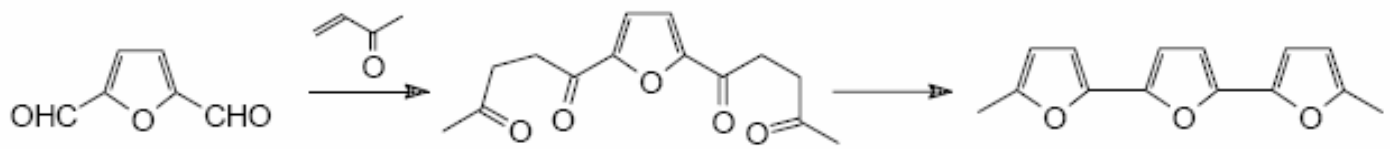

59

\section{Scheme 26}

The condensation of FDC with 1,3-diaminopropane ${ }^{164}$ on $\mathrm{Ba}^{+2}$ template resulted in the macrocycle 61 as the complex of barium. This compound was able to form complexes with such ions as $\mathrm{Cu}^{+2}$ and $\mathrm{Cu}^{+1}$.

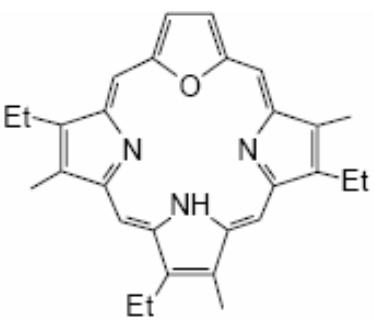

60

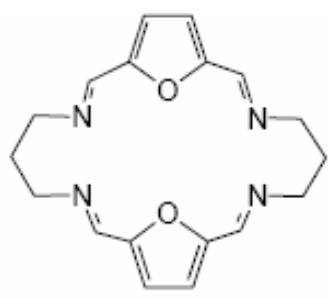

61

The similar condensation of FDC was performed ${ }^{165}$ with various $\alpha, \omega$-diamino ethers such as 1,8-diamino-3,6-dioxaoctane, 1,11-diamino-3,6,9-trioxaundecane, 1,2-bis-(2aminophenoxy)ethane, 1,3-bis-(2-aminophenoxy)propane. This reaction resulted in a series of macrocyclic compounds 62a-d having strong complexing properties towards ions such as: $\mathrm{Mg}^{+2}$, $\mathrm{Ba}^{+2}, \mathrm{Ca}^{+2}$ and $\mathrm{Sr}^{+2}$.

Majoral's group performed the synthesis of macrocyclic polyazaphosphonic 22- and 33membered ring systems $63 \mathbf{a}-\mathbf{b} .^{166-170}$ They made them by the condensation of FDC with phenylphosphonic acid dihydrazide.
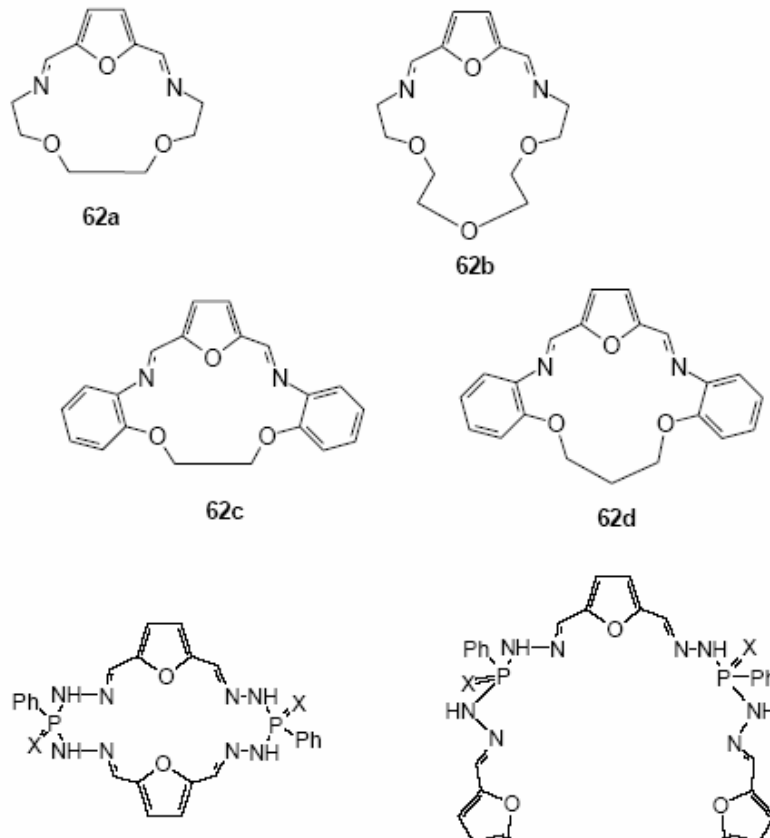

$63 a$

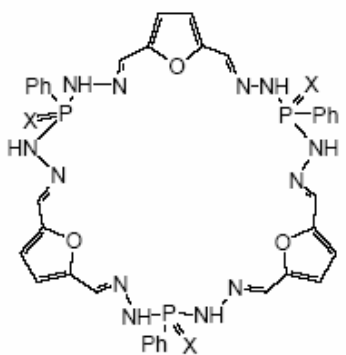

$63 b$ 
Clennan et al. ${ }^{171}$ reported results of their work on the chemical behaviour of FDC in the photochemical oxidation with oxygen. They performed ${ }^{1} \mathrm{H},{ }^{13} \mathrm{C}$ and ${ }^{17} \mathrm{O}$ NMR studies on products of the reaction.

Lumbroso et al. ${ }^{172}$ performed IR and dipole moment measurements to establish predominant conformational states. Finally, Scholtz et al. ${ }^{173}$ synthesised a radical-anion of FDC and measured its ESR spectrum at various temperatures.

\section{PART C: 2,5-FURANDICARBOXYLIC ACID (FDCA)}

2,5-Furandicarboxylic acid (FDCA) 40 was first detected in human urine. ${ }^{174}$ A healthy human produces $3-5 \mathrm{mg} /$ day. Numerous studies were undertaken to establish the metabolism of this compound and to determine the quantity, which is produced depending on the healthiness of the human. It was demonstrated, for example that the individual quantity of produced FDCA increased after alcohol consumption ${ }^{174}$ and after the injection of fructose. ${ }^{175}$ FDCA was detected also in the blood plasma. ${ }^{176,177}$

Studies were undertaken to find FDCA outside the human. When glucose was heated under a high pressure, FDCA was found to be one of formed products. ${ }^{178}$

Sugars reacting with amino acids undergo the Maillard reaction. This is a very complex process consisting of polycondensation and oxidation reactions. ${ }^{179-182}$ Furan derivatives, among them FDCA, were suggested to be the reason of browning, which is an optical evidence for the Maillard reaction. This suggestion is a good explanation for fruits darkening in the air. ${ }^{183-186}$

\section{Methods for synthesis of 2,5-furandicarboxylic acid (FDCA)}

Methods for the synthesis of the diacid $\mathbf{4 0}$ may be divided into three groups:

- Methods based on the dehydration of hexose derivatives

-Methods based on the oxidation of 2,5-disubstituted furans

-Methods based on catalytic conversions of various furan derivatives

First group is based on the acid-promoted triple dehydration of aldaric acids. (Scheme 27)
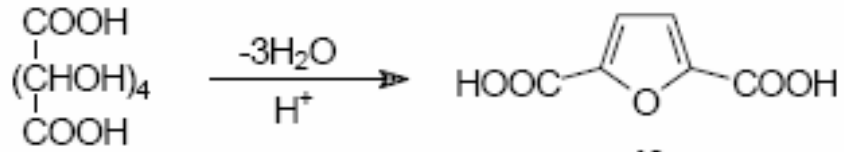

40

\section{Scheme 27}

Fittig and Heinzelman ${ }^{187}$ were the first who performed the regular synthesis of FDCA by the reaction of mucic (galactaric) acid with hydrobromic acid giving a full description of the obtained dehydromucic acid (dehydromucic or pyromucic acid, both are common names of 2,5furandicarboxylic acid). Later on, numerous chemists modified this method changing the nature of the dehydrating agent ${ }^{188-191}$ and the kind of the substrate ${ }^{192-197}$ All these reactions required drastic conditions - the temperature must be over $120{ }^{\circ} \mathrm{C}$, the required time of the reaction should exceed $20 \mathrm{~h}$. Moreover all these methods were not selective ${ }^{198}$ (a number of side-products was detected) and were inefficient (yields were less than 50\%).

Only one method from this group gave the prospectively efficient preparation of FDCA on a 
large scale. ${ }^{199}$ Diethyl $\alpha, \alpha^{\prime}$-dihydroxymuconate $\mathbf{6 4}$ was dehydrated in acidic conditions leading to diethyl 2,5-furandicarboxylate $\mathbf{6 5}$ in $95 \%$ yield.

Despite the described inconvenience, methods from this group were considered as easy enough in a work-up and have been utilised as laboratory preparative methods. ${ }^{200-204}$
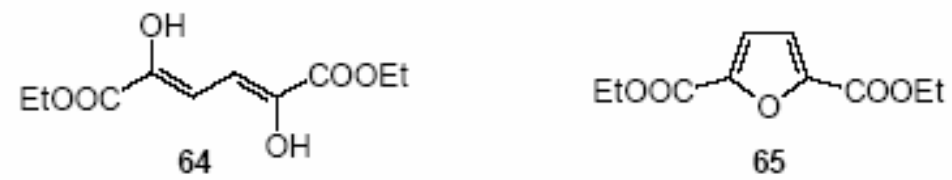

The second class includes reactions of the oxidation of various 2,5-disubstituted furans utilising a variety of inorganic oxidants. Several papers have been published, describing the synthesis of FDCA from furfural ${ }^{205-212}$. Furfural was oxidised to 2 -furoic acid with nitric acid and the latter was subsequently converted to its methyl ester. The ester was then undergone the reaction of chloromethylated at position 5 to give methyl 5-chloromethylfuroate. The latter was oxidised with nitric acid to afford dimethyl 2,5-furandicarboxylate, which, after the alkaline hydrolysis gave FDCA in 50\% yield. (Scheme 28)

It has been suggested ${ }^{145,207,211}$ that the reaction is more convenient and efficient when 5chloromethylfuroate is converted into methyl 5-acylmethyl-2-furoate $\mathbf{6 6}$ and the latter was oxidised to 2,5-furandicarboxylate. But according to my observation, it prolongs the time of the reaction and does not improve the yield much.

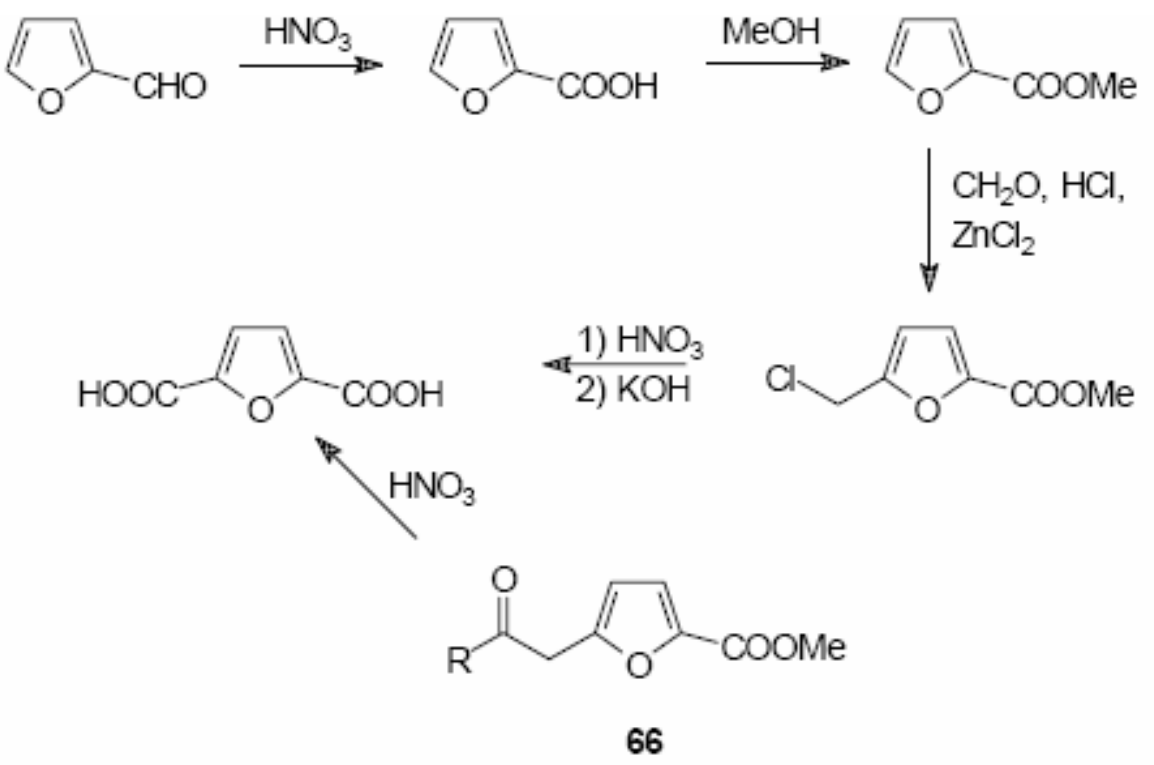

Scheme 28

As mentioned in PART A several significant works deal with the oxidation of 5hydroxymethylfurfural to FDCA. El-Hajj, ${ }^{44}$ Blanksma $^{72}$ and Cottier et al. ${ }^{100}$ performed studies on the oxidation of HMF with nitric acid to obtain the diacid 40. But these methods although efficient, were not selective - the presence of a significant amount of the side-product was detected. This subject was discussed in PART A of this article. 5-Chloromethylfurfural also has been oxidised ${ }^{11}$ with nitric acid resulting in FDCA in a high yield. 5-Hydroxymethyl-2-furoic acid was oxidised with nitric acid too, ${ }^{44,100}$ but selectivity of this reaction was similar to that 
obtained with HMF, but the yield was lower (47\%).

Morikawa $^{123}$ oxidised HMF with nitrogen dioxide in DMSO and nitric acid in DMSO affording the diacid $\mathbf{4 0}$ in $\mathbf{7 0 \%}$ yield.

Novitski et al. ${ }^{153}$ obtained FDCA by the oxidation of variously 5 -substituted 2 -furoic acids with sodium hypobromite. The same oxidant, ${ }^{153}$ when used in the oxidation of 2,5furandicarbaldehyde 19 led to the formation of FDCA in $83 \%$ yield.

Some attempts ${ }^{44,95}$ were made to oxidise FDC 19 with silver (I) oxide in an aqueous alkaline medium. Both methods turned out to be efficient, especially El-Hajj's one, ${ }^{44}$ which afforded FDCA in $80 \%$ yield.

Valanta $^{213}$ obtained the diacid $\mathbf{4 0}$ by the action of potassium permanganate on the mixture of 5-(1-propenyl)-2-furonitrile and furfurylidenepropionitrile. (Scheme 29)

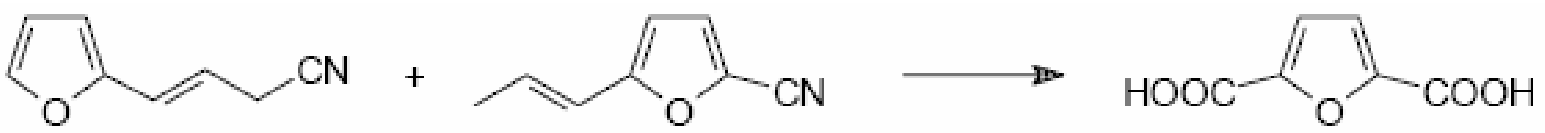

\section{Scheme 29}

5-Formyl-2-furoic acid has been oxidised ${ }^{214}$ with hydrogen peroxide in the presence of tertiary amines to give the diacid $\mathbf{4 0}$ in $90 \%$ yield. Hydrogen peroxide was also applied ${ }^{153}$ to the oxidation of 2,5-furandicarbaldehyde 19. The reaction was carried out in 1 molar aqueous sodium hydroxide, but FDCA was obtained in less than $60 \%$ yield.

Potassium ferrocyanide $\mathrm{K} 3[\mathrm{Fe}(\mathrm{CN}) 6]$ was used twice in the synthesis of FDCA. Cinneide ${ }^{215}$ reported the oxidation of 5-[(N-benzoyl)aminomethyl]-2-furoic acid 67, Brown ${ }^{216}$ performed the reaction with 5-methyl-2-furoic acid. But neither of these two methods was efficient enough to be considered as a potential industrial preparation. (Scheme 30)

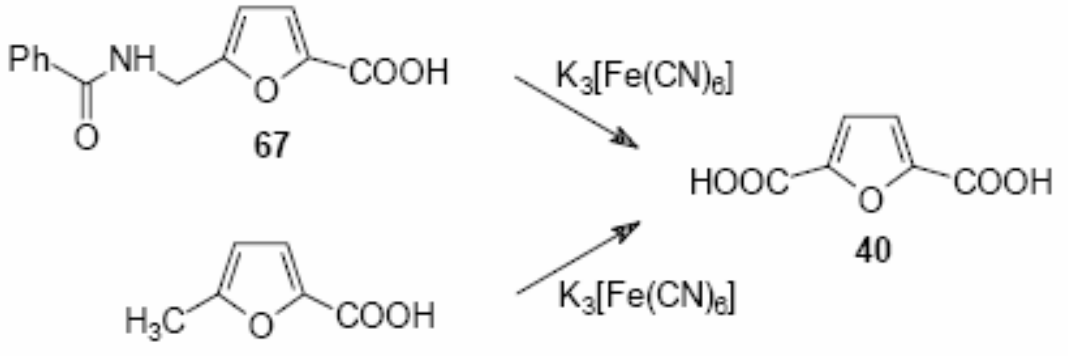

\section{Scheme 30}

The third group of methods for the preparation of the title compound $\mathbf{4 0}$ is based on catalytic reactions of furfural and 5-methyl-furfural as well as of HMF derivatives.

Andrisano $^{217}$ reported that potassium 2-furoate, when heated up to $300^{\circ} \mathrm{C}$ in a nitrogen atmosphere, underwent decarboxylation to furan with simultaneous carboxylation at position 5 to dipotassium 2,5-furandicarboxylate. (Scheme 31)
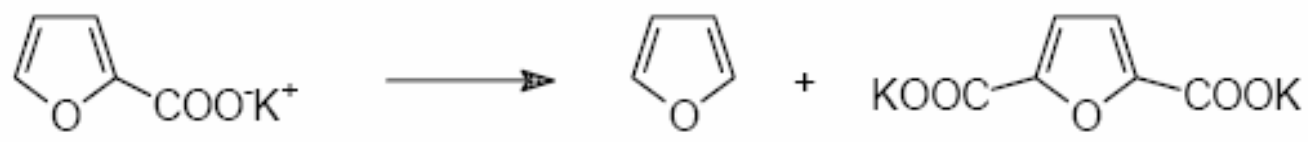

\section{Scheme 31}


Raecke ${ }^{218}$ carried out the synthesis of dipotassium 2,5-furandicarboxylate in the course of the pyrolytic reaction of potassium 2-furoate under a pressure of $50 \mathrm{~atm}$ and at a temperature of $320^{\circ} \mathrm{C}$. However, when the reaction was carried out in the absence of catalysts, the yield was rather lower. When Lewis acids such as $\mathrm{CdF}_{2}, \mathrm{CdCl}_{2}, \mathrm{CdI}_{2}$ or $\mathrm{ZnCl}_{2}$ were used as catalysts, the efficiency of the reaction improved much and the diacid $\mathbf{4 0}$ was obtained in $80 \%$ yield.

Catalytic oxidation of 5-methylfurfural require the liquid-phase reaction under pressure of 10-50 atm and $110-150{ }^{\circ} \mathrm{C}$. Moreover, this method requires such catalysts as $\mathrm{Ag}_{2} \mathrm{O}, \mathrm{CuO}, \mathrm{Al}_{2} \mathrm{O}_{3}$, or $\mathrm{Cr}_{2} \mathrm{O}_{3}{ }^{219-221} \mathrm{~A}$ mixture of cobalt, manganese and ammonium acetates has been proposed $^{219,220,222}$ (Scheme 32).

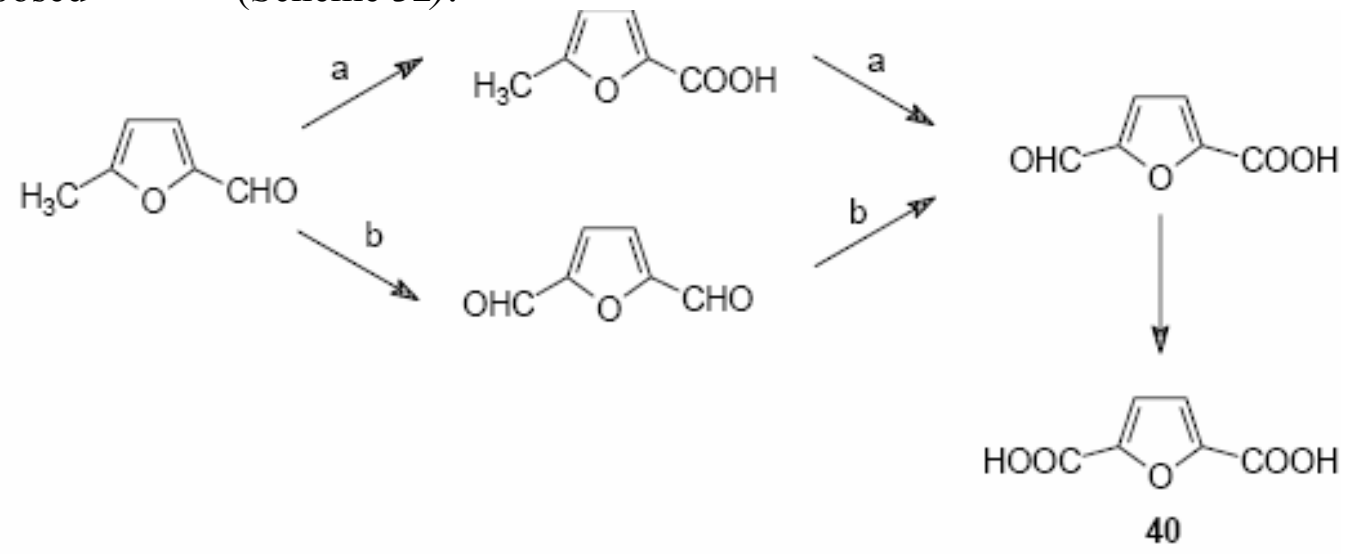

\section{Scheme 32}

When the mixture of silver and aluminium oxides (or silver oxide itself) was utilised as a catalyst ${ }^{219}$, the reaction proceeded through path ' $\mathrm{a}$ '. But the application of $\mathrm{CuO}-\mathrm{Ag}_{2} \mathrm{O}$ $\mathrm{Cr}_{2} \mathrm{O}_{3} / \mathrm{Al}_{2} \mathrm{O}_{3}{ }^{220,221}$ or $\mathrm{CuO}-\mathrm{Ag}_{2} \mathrm{O} / \mathrm{Al}_{2} \mathrm{O}_{3}$ catalytic systems favoured the path ' $\mathrm{b}$ '. The path ' $\mathrm{b}$ ' was also preferable, when the mixture of acetates was used. ${ }^{219,220,222}$

There are not so many papers describing the catalytic oxidation of HMF to the diacid $\mathbf{4 0}$. Van Bekkum $^{102}$ and Vinke ${ }^{103}$ oxidised HMF with noble metals as catalysts; their works are discussed in details in PART A of this article. Lew ${ }^{122}$ has patented very efficient methods for the synthesis of FDCA via the catalytic oxidation of HMF. Activated charcoal adsorbed on platinum was used as a catalyst and the author ${ }^{122}$ reported the isolation of FDCA in $95 \%$ yield. But when the catalytic Pt/C/ CuO-Ag2O mixture was applied, ${ }^{122}$ FDCA was obtained in 99\% yield. $\mathrm{Lew}^{122}$ suggested that HMF was oxidised to 5-hydroxymethylfuroic acid with $\mathrm{CuO}-\mathrm{Ag} 2 \mathrm{O}$ pair and the latter is subsequently oxidised to FDCA with charcoal-on-platinum catalyst. (Scheme 33)

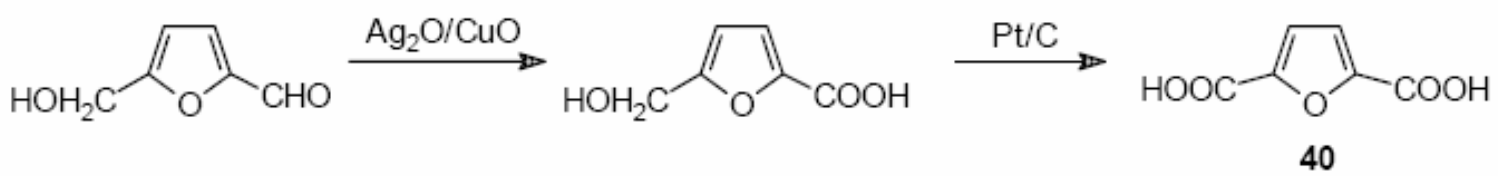

\section{Scheme 33}

In conclusion, the synthesis of 2,5-furandicarboxylic acid is much easier than the synthesis of HMF. Several reactions were found to be cheap and efficient enough to be utilised on an industrial-scale. 


\section{The chemistry and applications of 2,5-furandicarboxylic acid (FDCA)}

2,5-Furandicarboxylic acid is a very stable compound. Its physical properties, such as insolubility in most of common solvents (it is soluble exclusively in DMSO) and a very high melting point (it melts at $342{ }^{\circ} \mathrm{C}^{128}$ ) seem to indicate intermolecular hydrogen bonding as illustrated. $^{100 \mathrm{~b}}$

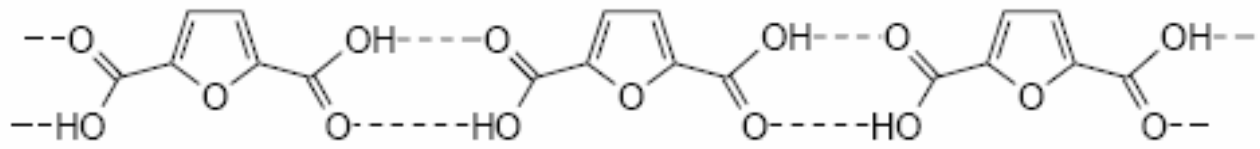

Despite its chemical stability, FDCA undergoes reactions typical for carboxylic acids, such as halogen substitution to give carboxylic dihalides, ${ }^{188}$ the ester formation ${ }^{190,196}$ and the formation of amides. ${ }^{188,196,223}$ All these reactions were elaborated in the beginning of $20^{\text {th }}$ or at the end of $19^{\text {th }}$ century. Newer methods have been described by Janda et al., ${ }^{224}$ who introduced the synthesis of 2,5-furandicarboxylic dichloride, by the reaction of FDCA with thionyl chloride. The synthesis of diethyl ester ${ }^{225}$ and dimethyl ester ${ }^{223}$ as well as the amidation ${ }^{226}$ have been reported.

There is a group of conversions that illustrates interesting reactivity of this compound. Lyalin and co-workers ${ }^{227}$ synthesized 2,5-bis-(trifluoromethyl)furan 68; and Grigorash et al $^{228}$ described the preparation of 5-trifluoromethyl-2-furoic acid 69. These two reactions proved that trifluoromethylation of FDCA can be performed selectively - one or both carboxylic groups can be substituted.

Klinhardt ${ }^{188}$ reported the synthesis of 5-nitro-2-furoic acid $\mathbf{7 0 .}$

The partial fluorisation of the furan ring in FDCA was also performed. ${ }^{229}$ It resulted in 2,5difluoro-2,5-di(trifluoromethyl)-2,5-dihydrofuran 71. The hydrogenation of FDCA ${ }^{230}$ led to 2,5dihydrofuran-2,5-dicarboxylic acid 72. (Scheme 34)

The most important group of FDCA conversions is undoubtedly the polymerisation. Malyshevskaya et al, $^{231}$ Krieger $^{232}$ and Sarzevska et al. ${ }^{233-234}$ estbilished the method for the preparation of numerous polyamides having interesting mechanical and physical properties. Polycondensation of FDCA with aromatic diamines gives polyamides in $90 \%$ yield. $^{235}$ Mitiakoudis $^{236}$ obtained polyamides bearing exclusively furan rings and he performed studies demonstrating that these polyamides are extremely thermally resistant. Smay ${ }^{237}$ synthesised a wide group of polyamides and polybenzimidazoles bearing furan rings. These polymers can be applied to the preparation of fibres widely utilised in the production of thermally resistant fabrics. Moreover, polyamides obtained by the condensation of the diacid $\mathbf{4 0}$ and benzidine derivatives ${ }^{238}$ presented a high resistance towards temperatures up to $500{ }^{\circ} \mathrm{C} .{ }^{238-241}$ Polyamides are also utilised for the preparation of membranes showing osmotic activity ${ }^{242}$. 


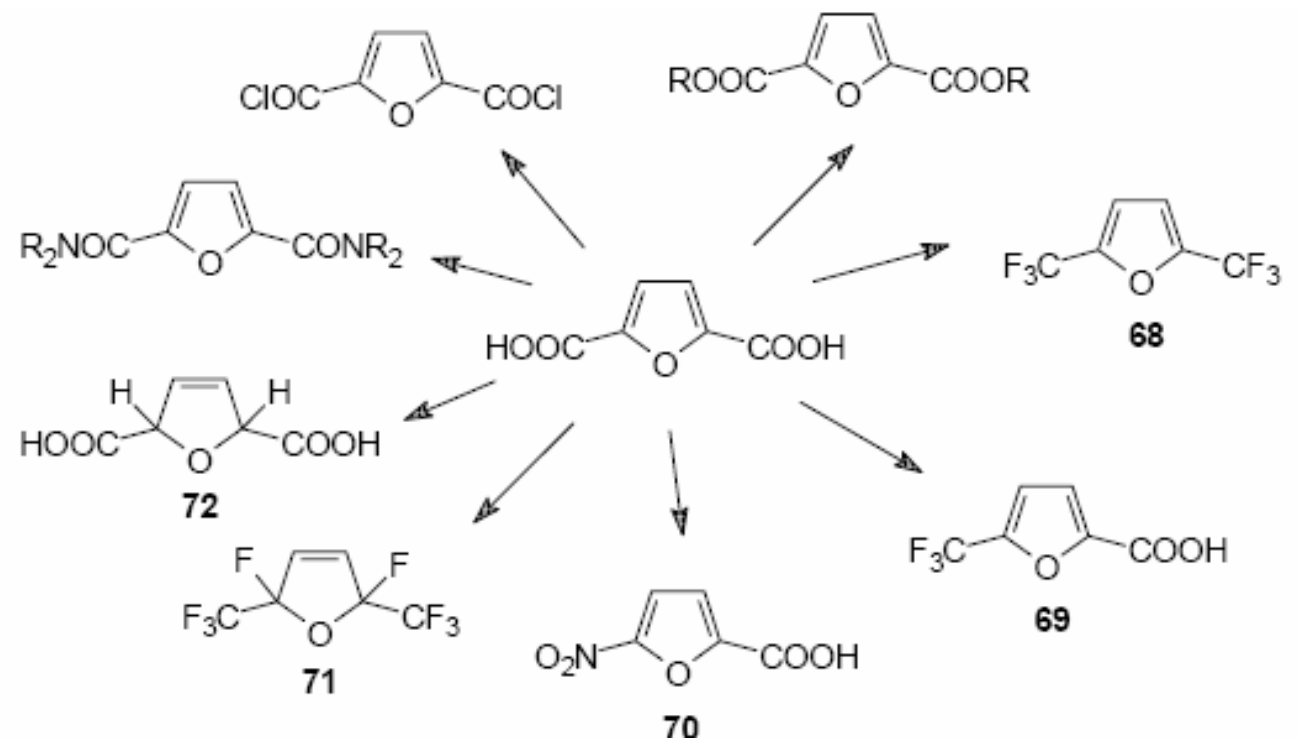

\section{Scheme 34}

Polyesters, have been widely studied. Lukes ${ }^{243}$ and Manasek ${ }^{244}$ performed the synthesis of polyesters by the condensation of FDCA with ethylene glycol, Akutin ${ }^{245}$ and Rodovilova ${ }^{246}$ studied its condensation with 4,4'-bisphenol. Products were thermally and mechanically resistant, colourless and fibres had a lower degree of the piling.

Similar properties characterised polyhydrazines synthesised by Frazier and Wallenberg ${ }^{247}$ as well as Heertjes and Kok. ${ }^{238}$

2,5-Furandicarboxylic acid was largely applied in pharmacology. It was demonstrated that its diethyl ester had a strong anaesthetic action similar to cocaine. ${ }^{248}$ Dicalcium 2,5furandicarboxylate was shown to inhibit the growth of Baccillus megatorium spora. ${ }^{249}$

Screening studies on FDCA-derived anilides $\mathbf{7 3}$ showed their important anti-bacterial action. ${ }^{250}$ The diacid itself is a strong complexing agent, ${ }^{251}$ chelating such ions as: $\mathrm{Ca}^{+2}, \mathrm{Cu}^{+2}$ and $\mathrm{Pb}^{+2}$, it is utilised in medicine to remove kidney stones. ${ }^{252}$
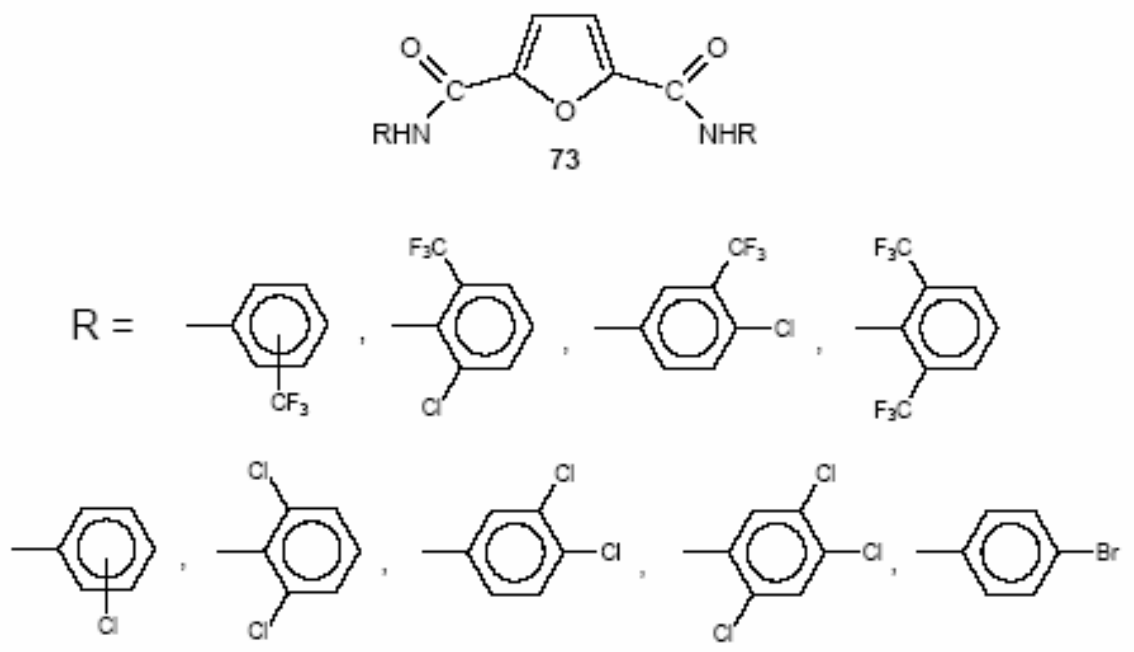

A very diluted solution of FDCA in tetrahydrofuran is utilised for preparing artificial veins for transplantation ${ }^{252}$. Treating them with this solution allows the cross-linking of peptide $\mathrm{NH} 2$ 
and $\mathrm{OH}$ groups, so that the intracellular matrix of the tissue is formed. The veins are chemically stable and have biophysical and biochemical properties analogous to natural organs, so that few cases of the rejection have been observed. ${ }^{252-253}$

At the beginning of this chapter, it was mentioned that FDCA is a chemically stable compound. This property has been well benefited in industry - FDCA as most of polycarboxylic acids is an ingredient of fire foams. Such foams help to extinguish fires in a short time caused by polar and non-polar solvents. ${ }^{254}$

\section{Conclusions}

I hope that these pages will convince chemists that 5-hydroxymethylfurfural and its derivatives are compounds of great importance in various branches of chemistry. HMF itself is an interesting raw material due to its high reactivity and the polyfunctionality; it is simultaneously a primary aromatic alcohol, an aromatic aldehyde and a furan ring system. Derivatives of HMF have already been utilised in agrochemistry as fungicides, in galvanochemistry as corrosion inhibitors, in cosmetic industry and as flavour agents.

HMF is a good starting material for the synthesis of precursors of various pharmaceuticals, thermo-resistant polymers and complex macrocycles. Among these precursors, one can find 2,5furandicarbaldehyde and 2,5-furandicarboxylic acid; these two compounds are described in detail in this article. The field of their applications is enormous - the dialdehyde offers itself to be the precursor for the synthesis of complexing macrocycles, oxo-porphirines, oxo-annulenes as well as mono- and bis alkenyl and alkynyl furans. The diacid is a building block for numerous polyesters and polyamides; its derivatives were found to be useful in pharmacology. No wonder then, that numerous methods for their preparation have been worked out and published.

It is also important that HMF shows a weak cytotoxicity and mutagenicity in human ${ }^{255}$. This fact should be appreciated, considering the high level of the risk during the work with the majority of other useful, multifunctional compounds.

As for the synthesis of HMF, there are still some unresolved problems. However, a high cost of the production of HMF is the most troublesome. Let me be allowed to quote Cottier and Descotes' remark concluding their article ${ }^{6}$ entitled "5-Hydroxyemthylfurfural syntheses and chemical transformations". They said there: “...With a more competitive price, HMF should offer new development in diversified fields..." and it is true, because costs, which should be covered just for obtaining HMF limit greatly the progress of studies on this interesting and promising compound. But in my modest opinion, studies on HMF and its derivatives should be continued.

\section{Acknowledgements}

I wish to thank very warmly Professor Romuald Skowroński from the University of Łódź, who taught me everything, what I know about being a scientist. I would also like to express my

special thanks to Doctor Louis Cottier and Professor Gérard Descotes for teaching me the chemistry of furans. 


\section{References}

1. Newth, F. H. Adv. Carbohydr. Chem. 1951, 6, 83.

2. Feather, M. S.; Harris, J.F. Adv. Carbohydr. Chem. 1973, 28, 161.

3. Gaset, A.; Gorrichon, J. P.; Truchot, E. Inf. Chim. 1981, 212, 179.

4. Faury, A.; Gaset, A.; Gorrichon, J. P. Inf. Chim. 1981, 214, 203.

5. Kuster, B. M. F. Starch/Stärke 1990, 42, 314.

6. Cottier, L.; Descotes, G. Trend. Heterocycl. Chem. 1991, 2, 233.

7. Dull, G. Chem. Ztg. 1895, 19, 216.

8. Kiermayer, J. Chem. Ztg. 1895, 19, 1003.

9. Fenton, H. J. H.; Gostling, M. J. Chem. Soc. 1899, 75, 423.

10. Fenton, H. J. H.; Gostling, M. J. Chem. Soc. 1901, 79, 807.

11. Fenton, H. J. H.; Robinson, F. J. Chem. Soc. 1909, 95, 1334.

12. Middendorp, J. A. Rec. trav. chim. 1919, 38, 1.

13. Reichstein, T.; Zschokke, H. Helv. Chim. Acta 1932, 15, 249.

14. Reichstein, T. Helv. Chim. Acta 1926, 9, 1066.

15. Haworth, W. N.; Jones, W. G. M. J. Chem. Soc. 1944, 667.

16. Karashima, J. Zeit. physiol. Chem. 1928, 180, 241.

17. Moye, C. J. Rev. Pure and Appl. Chem. 1964, 14, 161.

18. Moore, J.A.; Kelly, J.E. Macromolecules 1978, 11, 568.

19. Gandini, A. Encycl. Polym. Sci. Eng. 1987, 7, 454.

20. Rapp, M. K. Ger. Patent, 3601281, 1987; Chem. Abstr. 1987, 107, 154231r.

21. Antal, M. J.; Mok, W. S. L.; Richards, G. N. Carbohydr. Res. 1990, 199, 91.

22. Van Dam, H. E.; Kieboom, A. P. G.; Van Bekkum, H. Starch/Stärke 1986, 38, 95.

23. Cottier, L.; Descotes, G.; Neyret, C.; Nigay, H. Industries Aliment. Agricol. 1989, 567.

24. Bonner, W. A.; Roth, M. J. Am. Chem. Soc. 1959, 81, 5454.

25. Bonner, W. A. J. Chem. Soc. 1960, 787.

26. Morikawa, S. Noguchi Kenkyusho Jiho 1978, 21, 25; Chem. Abstr. 1979, 90, 103740 d.

27. Mednick, M. L. Chem. Eng. News 1961(11), 75.

28. Mednick, M. L. J. Org. Chem. 1962, 27, 398.

29. Nakamura, Y. Japan.Patent, 8013243, 1980; Chem. Abstr. 1980, 93, 26260e.

30. Nakamura, Y. Noguchi Kenkyusho Jiho 1980, 23, 25; Chem. Abstr. 1981, 94, 156646s.

31. Fayet, C.; Gelas, J. Carbohydr. Res. 1983, 122, 59.

32. Smith, N. H. US Patent 3118912, 1964; Chem. Abstr. 1964, 60, P11986a.

33. Garber, J. D.; Jones, R. E. US Patent 2929823, 1960; Chem. Abstr. 1960, 54, 17416 i.

34. Hales, R. A.; Le Maistre, J. W.; Orth, G. O. US Patent 3071599 (1963); Chem. Abstr. 1963, 59, P576a.

35. Atlas Powder Co., Brit. Patent, 876463, 1960; Chem. Abstr. 1962, 56, P4732d.

36. Nakamura, Y. Noguchi Kenkyusho Jiho 1981, 24, 42; Chem. Abstr. 1981, 94, 156646s.

37. Fleche, G.; Gaset, A.; Gorrichon, J. P.; Truchot, E.; Sicard, P. Fr. Patent Appl., 2464260, 1981; Chem. Abstr. 1982, 96, P6552k.

38. Rigal, L.; Gorrichon, J. P.; Gaset, A.; Heughebaert, J. C. Biomass 1985, 7, 27.

39. Noguchi Institut, Japan.Patent, 81139473 (1981); Chem. Abstr. 1982, 96, P68801z. 
40. Morikawa, S.; Nakamura, Y. Bull. Chem. Soc. Jpn. 1980, 53, 3705.

41. Noguchi Innstitut, Japan.Patent, 81138177, 1981; Chem. Abstr. 1982, 96, P85408u.

42. Mercadier, D. L.; Rigal, L.; Gaset, A.; Gorrichon, J. P. J. Chem. Technol. Biotechnol., 31, 489 (1981).

43. Rigal, L.; Gaset, A.; Gorrichon, J. P. Ind. Eng. Chem. Prod. Res. Dev. 1981, 20, 719.

44. El-Hajj, T.; Masroua, A.; Martin, J. C.; Descotes, G. Bull. Soc. Chim. Fr. 1987, 855.

45. Cottier, L.; Descotes, G.; Neyret, C.; Nigay, H. (Beghin-Say Co.), Fr. Patent, 9008065 , 1990 and 9011479, 1990; Chem. Abstr. 1992, 117, 48323u and Chem. Abstr. 1992, 117, $90121 b$.

46. Shur, A. M.; Roitburd, C. V.; Yazlovetskii, I. G. Tr. Kishinev. Politekh. Inst. 1966, N.5, 67 Chem. Abstr. 1967, 67, 99923w.

47. Brown, D. W.; Floyd, A.J.; Kinsmann, R. G.; Roshan-Ali, Y. J. Chem. Technol. Biotechnol. 1982, 32, 920.

48. Smythe, B. M.; Moye, C. J. US Patent, 3219484, 1961; Chem. Abstr. 1966, 64, P8468g.

49. Smythe, B. M.; Moye, C. J. US Patent, 3290263, 1965; Chem. Abstr. 1967, 66, 65810w.

50. Husau, R. M.; Munavu, R. M. Biomass 1987, 13, 67.

51. Teunissen, H. P. Rec. trav. chim. 1931, 50, 1.

52. Peniston, Q. P. 2750394, 1956; Chem. Abstr. 1957, 51, $1284 \mathrm{~b}$.

53. Kuster, B. M. F. Carbohydr. Res. 1977, 54, 177.

54. Kuster, B. M. F.; Laurens, J. Starch/Stärke 1977, 29, 172.

55. Kuster, B. M. F.; Temmink, H. M. G. Carbohydr. Res. 1977, 54, 185.

56. Kuster, B. M. F. Starch/Stärke 1977, 29, 99.

57. Neyret, C. Ph.D. Thesis, Université Lyon 1, Lyon 1990.

58. Ponder, G. R.; Richards, G. N. Carbohydr. Res. 1993, 244, 341.

59. Nakama, A.; Kim, E. H.; Shinohara, K.; Omura, H. Biosci. Biotechnol. Biochem. 1993, 57, 1757.

60. Salomon, C. J.; Mata, E. G.; Mascaretti, O. A. Tetrahedron 1993, 49, 3691.

61. Sumoto, K.; Irie, M.; Mibu, N.; Miyano, S.; Nakashima, Y. Chem. Pharm. Bull. 1991, 39, 792.

62. Grin', S. A.; Tsimbalev, S. R.; Gel'fand, S. Yu. Russ. J. Appl. Chem. 1994, 67, 1330.

63. Isaacs, N. S.; Coulson, M. J. Phys. Org. Chem.1996, 9, 639.

64. Chmielewski, P. J.; Latos-Grażyński, L.; Olmstead, M. M.; Balch, A. L. Chem. Europ. J. 1997, 3, 268.

65. Tawara, J. N.; Johnson, J. J.; Goodall, M. J. J. Agric. Food. Chem.1996, 44, 3983.

66. Ichigawa, K.; Kinoshita, T.; Sankawa, U. Chem. Pharm. Bull. 1989, 37, 345.

67. Fernandez, L. E.; Valiente, O. G.; Garcia, R.; Castro, H. V.; Machytka, D. Carbohydr. Res. 1987, 163, 143.

68. Numata, A.; Takahashi, C.; Fujiki, R.; Kitano, E.; Kitajima, A.; Takemura, T. Chem. Pharm. Bull. 1990, 38, 2862.

69. Ayer, W. A.; Racok, J. S. Can. J. Chem. 1990, 68, 2085.

70. Shimizu, M.; Zenko, Y.; Tanaka, R.; Matsuzawa, T. Chem. Pharm. Bull. 1993, 41, 1469.

71. Hsiao, J. J.; Chiang, H. C. Phytochemistry 1995, 39, 899.

72. Blanksma, J. J. Chem. Weekblad. 1909, 6, 717. 
73. Constantin, J. M.; Humphreys, T. W.; Lange, H. B.; Shero, D.; Wagner J. R. (Merck \& Co), US Patent, 3080279, 1963; Chem. Abstr. 1963, 58, P10679c.

74. Hartzler, H. D. (Dupont de Neymours), US Patent, 4017 313, 1977; Chem. Abstr. 1977, 87, P46602x.

75. Wahhab, A. J. Am. Chem. Soc. 1948, 70, 3580.

76. Cope, A. C. US Patent, 3079449 1963; Chem. Abstr. 1963, 59, 8705c.

77. Bicker, R. DOS 3309564, 1984; Chem. Abstr. 1985, 102, P45763s.

78. Timko, J. M.; Cram, D. J. J. Am. Chem. Soc. 1974, 96, 7159.

79. Chundury, D.; Szmant, H. H. Ind. Eng. Chem. Prod. Res. Dev. 1981, 20, 158.

80. Bredereck, A. Chem. Ber. 1932, 65, 1110.

81. Garber, J. D.; Jones, R. E. US Patent. 2995581, 1961; Chem. Abstr. 1962, 56, P8691e.

82. Cottier, L.; Descotes, G.; Nigay, H.; Parron, J. C.; Gregoire, V. Bull. Soc. Chim. Fr. 1986, 844.

83. Cottier, L.; Descotes, G. private information of unpublished results.

84. Lichtenthaler, F. W. Zuckerind. 1990, 115, 198.

85. Lichtenthaler, F. W.; Martin, D.; Weber, T.; Schiweck, H. Liebigs Ann. Chem. 1993, 967.

86. El-Hajj, T.; Martin, J. C.; Descotes, G. J. Heterocyclic Chem. 1983, 20, 233.

87. Cottier, L.; Descotes G.; Lewkowski, J. Synth. Commun. 1994, 24, 939.

88. Newth, F.H.; Wiggins, L. F. J. Chem. Soc. 1947, 396.

89. Pavlov, P.; Kulnievich, V.G. Khim. Geterosikl. Soed. 1986, 22, 181.

90. Fischer, E.; von Neymann, H. Chem. Ber. 1914, 47, 973.

91. Hamada, K.; Yoshihara, H.; Suzukamo, G. Chem. Lett. 1982, 617.

92. Hamada, K.; Yoshihara, H.; Suzukamo, G. Europ. Patent Appl., EP 79206, 1983; Chem. Abstr. 1983, 99, 139750g.

93. Hibbert, H.; Hill, H.S. J. Am. Chem. Soc. 1923, 45, 176.

94. Calzada, J. G.; Hooz, J. Organic Syntheses 1974, 54, 63.

95. Cooper, W. F.; Nuttall, W. H. J. Chem. Soc. 1912, 101, 1074.

96. Cooper, W. F.; Nuttall, W. H. J. Chem. Soc. 1911, 99, 1193.

97. Reijendam, J. W.; Heeres, G. J.; Janssen, M. J. Tetrahedron 1970, 26, 1291.

98. Morikawa, S.; Terakate, S. Japan.Patent, 7909260, 1979; Chem. Abstr. 1979, 90, P186770w.

99. Morikawa, S. Japan.Patent, 8049368, 1980; Chem. Abstr. 1980, 93, 239196 a.

100.(a) Cottier, L.; Descotes, G.; Lewkowski J.; Skowroński, R. Polish J. Chem. 1994, 68, 693

(b) Lewkowski, J., unpublished results.

101.Cottier, L.; Descotes, G.; Lewkowski, J.; Skowroński, R. Org. Prep. Proced. Int. 1995, 27, 564.

102.van Bekkum, H. Studies on Selective Carbohydrate Oxidation, In Carbohydrates as Organic Raw Materials; Ed. Lichtenthaler, F.W., VCH: Weinham, 1991.

103. Vinke, P. Ph.D. Thesis, Technical University in Delft; Delft, 1991.

104.Cottier, L.; Descotes, G.; Lewkowski J.; Skowroński, R.; Viollet, E. J. Heterocycl. Chem. 1995, 32, 927.

105.Durant-Pinchard, M. Fr. Patent Appl., 2556344, 1985; Chem. Abstr. 1986, 104, 131944z.

106.Schiavo, V.; Descotes, G.; Mentech, J. Bull. Soc. Chim. Fr. 1991, 704. 
107.Finan, P. A. J. Chem. Soc. 1963, 3917.

108.Reynolds, H. C.; Jones, R. E.; Garber, J. D. (Merck \& Co), US Patent, 3014926, 1961; Chem. Abstr. 1962, 56, P12856f.

109. Strain, H. J. Am. Chem. Soc. 1930, 52, 1216.

110. Müther, G.; Tollens, B. Chem. Ber. 1904, 37, 303.

111. van Eckenstein, W. A.; Blanksma, J. J. Chem. Zentralblatt 1909, 1909 I, 1509.

112. Erdmann, E.; Schaefer, C. Chem. Ber. 1910, 43, 2392.

113. Kallinich, H. Archiv. der Pharm. 1958, 291, 274.

114. Blanksma, J. J. Rec. trav. chim. 1939, 58, 497.

115. Sattler, L.; Zerban, F. W.; Clarck, G. L.; Chu, C. C. J. Am. Chem. Soc. 1951, 73, 5908.

116. Iseki, T. Zeit. physiol. Chem. 1933, 216, 127.

117. Drechsler, G.; Kopperschlaeger, G. J. prakt. Chem. 1965, 27, 258.

118. Skowroński, R.; Grabowski, G.; Lewkowski, J.; Descotes, G.; Cottier L.; Neyret, C. Org. Prep. Proced. Int. 1993, 25, 321.

119. Nikolov, M.; Poneva, M. Spectrosc. Lett. 1987, 20, 821.

120. Mouloungui, Z.; Delmas, M.; Gaset, A. Synth. Commun. 1984, 14, 701.

121. Wierenga, W.; Evans, B. R.; Walterson, J. A. L. J. Am. Chem. Soc. 1979, 101, 1334.

122. Lew, B. W. (Atlas Chem.Ind.), US Patent, 3326944, 1967; Chem. Abstr. 1968, 68, P49434n.

123. Morikawa, S. Noguchi Kenkyusho Jiho 1979, 22, 20; Chem. Abstr. 1980, 92, 198181 d.

124. Blanksma, J. J. Rec. trav. chim. 1910, 29, 403.

125. Lillwitz, L. D. (Quaker Oats Co), US Patent, 4089871, 1978; Chem. Abstr. 1978, 89, P129386x.

126. Choudury, P. K. J. Sci. Ind. Res. 1957, 16B, 289.

127. Horvat, J.; Klaič, B.; Metelko, B.; Sunjic, V. Tetrahedron Lett. 1985, 26, 2111.

128. Haworth, W. N.; Jones, W. G. M.; Wiggins, L.F. J. Chem. Soc. 1945, 1.

129. Snyder, F. H. (Dendrol Inc.), US Patent, 2776948, 1957 and US Patent 2804445, 1957;

Chem. Abstr. 1958, 51, 5464e and Chem. Abstr. 1958, 52, 3407g.

130. Snyder, F. H. (Dendrol Inc.), US Patent, 2875180 (1959); Chem. Abstr. 1959, 53, 10842 a.

131. Zech, J. D.; Hunter, R. M. (Atlas Chem.Ind.), US Patent, 3392148, 1968; Chem. Abstr. 1968, 69, 52729p.

132. Kawana, O.; Nakamura, Y.; Yoshihiro, Y. Nippon Kogaku Zaishi 1983, 12, 1747. Chem. Abstr. 1984, 100, 156445t.

133. El-Hajj, T. Ph.D. Thesis, Université Lyon 1, Lyon 1983.

134. Grabowski, G.; Lewkowski, J.; Skowroński, R. Electrochimica Acta 1991, 36, 1995.

135. Grabowski, G.; Lewkowski, J.; Skowroński, R. Polish Pat., PL 161831, 1993; Chem. Abstr. 1995, 123, P299957x.

136. Skowroński, R.; Cottier, L.; Descotes, G.; Lewkowski, J. Synthesis 1996, 1291.

137. Pastour, P.; Plantard, C. C. R. Acad. Sci., Ser.C 1966, 262, 1539.

138. Goldfarb, Y. L.; Rogowik, V.I. USSR Pat., 184877, 1966; Chem. Abstr. 1967, 66, P115590x.

139. Zaluski, M.; Robba, M.; Bonhomme, M. Bull. Soc. Chim. Fr. 1970, 1445.

140. Feringa, B. L.; Hulst, R.; Rikers, R.; Brandsma, L. Synthesis 1988, 316. 
141. Carpenter, A. J.; Chadwick, D. J. Tetrahedron 1985, 41, 3803.

142. Bauer, S.; Spiteller, G. Liebigs Ann. Chem. 1985, 813.

143. Oleinik, A. F.; Novitski, K. Y. Zhur. Org. Khim. 1970, 6, 2632.

144. Novitski, K. Y.; Volkov, V. P.; Yurev, Y. R. Zhur. Obshch. Khim. 1961, 31, 538.

145. Moldenhauser, O.; Trautmann, G.; Irion, W.; Peluger, R.; Doser, H.; Mastaglio, D.; Marwitz, H. Liebigs Ann. Chem. 1953, 580, 169.

146. Johnson, R. G.; Kidd, D. J. J. Chem. Soc. 1964, 4730

147. Stibor, J.; Prohalkova, H.; Janda, M.; Strogl, J. Zeit. Chem. 1971, 11, 17.

148. Takada, H. Jpn.Kokai Tokkyo Koho 91101672, 1991; Chem. Abstr. 1991, 115, 114337.

149. Maraval, M. Ph.D. Thesis, Ecole Nationale Polytechnique de Toulouse, Toulouse 1985.

150. Garcia, Y. Synthese du FDC a partir de HMF pur, Toulouse 1989.

151. Iovel, I. G.; Gavars, M.; Gaukhman, A. P.; Shimanskaya, M. V. USSR Pat., 1342903, 1987; Chem. Abstr. 1988, 108, P21707z.

152. Dominguez, C.; Escobar, G.; Plumet, J.; Gaset, A.; Rigal, L. An. Quim. 1986, 82C, 241. Chem. Abstr. 1988, 108, 5792t.

153. Novitski, K. Y.; Volkov, V. P.; Yurev, Y. K. Zhur. Obshch. Khim. 1962, 32, 399.

154. Viallet, A.; Gandini, A. J. Photochem. and Photobiol. 1990, 54, 129.

155. Dominguez, C.; Csáky, A. G.; Magano, J.; Plumet, J. Synthesis 1989, 172.

156. Dominguez, C.; Csáky, A. G.; Plumet, J.; Rigal, L.; Tauler, C. Synth. Commun. 1991, 21, 1251.

157. Mansfield, J. W.; Porter, A. E. A.; Widdowson, D. A. J. Chem. Soc., Perkin I 1973, 2557.

158. Tsibizov, Yu. N.; Pozmarski, F. J.; Simonov, A. M.; Knyazhanski, M. I.; Stryukov, M. B. USSR Patent, 413861 (1974); Chem. Abstr. 1975, 82, P78723a.

159. Tsibizov, Yu. N.; Pozmarski, F. J.; Simonov, A. M.; Knyazhanski, M. I.; Stryukov, M. B. Ger.Patent, 2349803 (1975); Chem. Abstr. 1975, 83, P81241b.

160. Daub, J.; Salbeck, J.; Knöchel, T.; Fischer, C.; Kunkely, H.; Rapp, K. M. Angew. Chem. Int. Ed. 1989, 28, 1194.

161. Crasp, T. M.; Sargent, M. V. J. Chem. Soc., Perkin I 1973, 2961.

162. (a) Ogawa, H.; Sadakari, N.; Imoto, T.; Miyamoto, I.; Kato, H.; Taniguchi, Y. Angew. Chem. Int. Ed. 1983, 22, 417. (b) Badger, G. M.; Elix, J. A.; Lewis, G.E. Austral. J. Chem. 1966, 19, 1221.

163. Broadhurst, M. J.; Grigg, R.; Johnson, A. W. J. Chem. Soc. C 1971, 3681.

164.(a) Nelson, S. M.; Esho, F.; Lavery, A.; Drew, M. G. B. J. Am. Chem. Soc. 1983, 105, 5693. (b) Drew, M. G. B.; Esho, F.; Nelson, S. M. J. Chem. Soc. Dalton Trans. 1983, 1653. (c) Nelson, S. M.; Esho, F.; Drew, M. G. B. J. Chem. Soc. Dalton Trans. 1983, 1653.

165. Fenton, D. E.; Cook, D. H.; Nowell, I. W.; Walker, P. E. J. Chem. Soc., Chem. Comm. 1977, 623.

166. Majoral, J. P.; Badri, M.; Caminade, A. M.; Delmas, M.; Gaset, A. Inorg. Chem. 1988, 27, 3873.

167. Majoral, J. P.; Badri, M.; Caminade, A. M. Heteroatom Chem. 1991, 2, 45.

168. Majoral, J. P.; Badri, M.; Caminade, A. M.; Gorgues, A.; Delmas, M.; Gaset, A.

Phosphorus Sulfur Silicon 1990, 49, 413.

169. Badri, M.; Majoral, J. P.; Caminade, A. M.; Delmas, M.; Gaset, A.; Gorgues, A.; Jaud, J. J. 
Am. Chem. Soc. 1990, 112, 5618.

170. Oussaid, B.; Garrigues, B.; Jaud, J.; Caminade, A. M.; Majoral, J. P. J. Org. Chem. 1993, 58,4500 .

171. Clennan, E. L.; Mehrsheikh-Mohammadi, M. E. J. Am. Chem. Soc. 1984, 106, 7112.

172. Lumbroso, H.; Cure, J.; Descotes, G.; Grassi, A. J. Mol. Struct. 1989, 196, 227.

173. Scholz, M.; Gescheidt, G.; Daub, J. J. Chem. Soc. Chem. Commun. 1995, 803.

174. Witten, T. A.; Levine, S. P.; Killan, M.; Boyle, P.; Harkey, S. Clin. Chem. 1973, 19, 963;

Chem. Abstr. 1974, 80, p575t.

175. Jellum, E.; Borresen, H.; Eldorn, L. Clin. Chim. Acta 1973, 47, 191; Chem. Abstr. 1974, 80, p78540x.

176. Koide, K.; Toyama, J.; Inoue, N.; Koshikawa, S.; Akizawa, T.; Takahashi, K. Jpn. J.

Nephrol. 1986, 28, 1481; Chem. Abstr. 1987, 106, p192091g.

177. Pinkston, D.; Spiteller, G.; von Hemming, H.; Matthaei, D. J. Chromatogr. 223, 1 (1982).

178. Durman, D. G.; Hune, C. T.; Taylor, R. B.; Int. J. Pharm. 1982, 12, 31.

179. Maillard, L. C.; C. R. Acad. Sci., Ser. C 1912, 154, 66.

180. Maillard, L. C. Ann. Chim. (Roma) 1916, 5, 258; Chem. Abstr. 1916, 10, 591.

181. Hayase, F.; Kim, S. B.; Kato, H. Agric. Biol. Chem. 1984, 48, 271.

182. Barbetti, P.; Chiappini, J. Ann. Chim. (Roma) 1976, 66, 485; Chem. Abstr. 1978, 88, $4555 f$.

183. Cavalieri, L. F.; Wolfrom, M. L. J. Am. Chem. Soc. 1946, 68, 2022.

184. Wolfrom, M. L.; Cavalieri, L. F.; Cavalieri, D. K. J. Am. Chem. Soc. 1947, 69, 2411.

185. Wolfrom, M. L.; Schuetz, R. D.; Cavalieri, L. F. J. Am. Chem. Soc. 1948, 70, 514.

186. Wolfrom, M. L.; Schuetz, R. D.; Cavalieri, L. F. J. Am. Chem. Soc. 1949, 71, 3518.

187. Fittig, R.; Heinzelmann, H. Chem. Ber. 1876, 9, 1198

188. Klinkhardt, A. J. prakt. Chem. 1882, 25, 41.

189. Seelig, E. Chem. Ber. 1879, 12, 1083.

190. Tollens, B.; Yoder, P. A. Chem. Ber. 1901, 34, 3446.

191. Ackman, R. G.; Brown, W. H.; Wright, G. F. J. Org. Chem. 1955, 20, 1147.

192. Fischer, E. Chem. Ber. 1891, 24, 2140.

193. Sohst, O.; Tollens, B. Liebigs Ann. Chem. 1888, 245, 1.

194. Schrotter, S. Monatsch. Chem. 1888, 9, 443.

195. Phelps, I. K.; Hale, W. J. Am. Chem. J. 1901, 25, 445.

196. Hill, H. B. Am. Chem. J. 1901, 25, 439.

197. Tieman, S.; Haarmann, D. Chem. Ber. 1886, 19, 1257.

198. Cope, A. C.; Keller, R. T. J. Org. Chem. 1956, $21,141$.

199. Kuhn, R.; Dury, K. Liebigs Ann. Chem. 1951, 571, 44.

200. Gaset, A.; Lewkowski, J.; Rigal, L.; Sene, B. unpublished results.

201. Kiss, J.; Furter, H.; Lohse, F.; Hardegger, E. Helv. Chim. Acta 1961, 44, 141.

202. Franck, R. W.; Yanagi, K. Tetrahedron Lett. 1966, 2905.

203. Franck, R. W.; Yanagi, K. J. Org. Chem. 1968, 33, 811.

204. Kelly, J. E. Ph.D. Thesis, Technical University Reusslaer, 1975.

205. Andrissano, R. Boll. Sci. Fac. Chim. Ind. Bologna 1949, 7, 58; Chem. Abstr. 1950, 44, 9404d. 
206. Andrissano, R. Ann. Chim. (Roma) 1950, 40, 30; Chem. Abstr. 1951, 45, 602g. 207. Hachihama, Y.; Shono, T.; Hyono, T. Technol. Repts. Osaka Univ. 1958, 8, 475.

208. Tundo, A. Boll. Sci. Fac. Chim. Ind. Bologna 1956, 14, 63; Chem. Abstr. 1957, 51, 5748g.

209. Mndzhoyan, A. L.; Aroyan, A. A. Dokl. Akad. Nauchn. Amayan. SSR 1957, 25, 267; Chem. Abstr. 1958, 52, p12834g.

210. Moshkin, P. A.; Preobrazhenskaya, E. A.; Lutkova, V. I.; Kutsenko, N. J.; Razumova, N. N.; Brezina, B. B.; Shamagina, N. N. Plast. Massy 1970, 26; Chem. Abstr. 1971, 74, p76681w.

211. Gonis, G.; Amstutz, E. D. J. Org. Chem. 1962, 27, 2946.

212. Mndzhoyan, A. L.; Oganesyan, R. S. Sint. Geterosikl. Soedin. Akad. Nauk. Arm. SSR, Inst.Tonkoi. Org. Khim. 1966, 7, 62; Chem. Abstr. 1968, 68, p104860a.

213. Valanta, M.; Janda, M.; Novitski, K. Y. Z. Chem. 1969, 9, 449.

214. Krapivin, G. D.; Kaklyugina, T. Ya.; Badovskaya, L. A.; Kul'nevich, V. G. Tr. Kuban. Unt 1976, 225, 20; Chem. Abstr. 1978, 88, p37046n.

215. Cinneide, R. O. Proc. Roy. Irish Acad. 1943, 49B, 143; Chem. Abstr. 1944, 38, 1230.

216. Brown, E. V. Iowa State Coll., J. Sci. 1937, 11, 227; Chem. Abstr. 1937, 31, p8528.

217. Andrisano, R.; Angeloni, A. S. Ann. Chim. (Rome) 1963, 53, 1658; Chem. Abstr. 1964, 60, p13208h

218. Raecke, B. Angew. Chem. 1958, 70, 1.

219. Slavinskaya, V. A.; Kreile, D. R.; Dziluma, E.; Eglite, D.; Milmanis, I.; Korchogova, E. Kh.; Avots, A.; Pinka, U. Tezisy Dokl. Resp. Konf. Okislitel'nomu Geterogennomu Katal. $3^{\text {rd }}$, 1976, 199; Chem. Abstr. 1978, 89, 146670c.

220. Slavinskaya, V. A.; Kreile, D. R.; Eglite, D. Ya.; Kruminya, L. Ya. React. Kinet. Catal. Lett. 1979, 11, 215.

221. Kreile, D. R.; Novikov, Yu. D.; Sile, D.; Eglite, D. Ya.; Slavinskaya, V. A. Latv. PSR. Zinat. Akad. Vestis. Khim. Ser. 1978, 4, 483; Chem. Abstr. 1978, 89, p197240v.

222. Kreile, D; Sile, D.; Krumina, L.; Strautina, A.; Slavinskaya, V. A. Zh. Vses. Khim, O-va 1977, 22, 98; Chem. Abstr. 1977, 86, p139722f.

223. Oae, S.; Furukawa, N.; Watanabe, T.; Otsuji, Y.; Hamoda, M. Bull. Chem. Soc. Jpn. 1965, $38,1247$.

224. Janda, M.; Valenta, H.; Hrdy, I.; Hurkova, J.; Strogl, J.; Stibor, J.; Holy, P.; Bartizal, J. CS Patent, 188,011, 1982; Chem. Abstr. 1982, 97, p72244h.

225. Kuhn, R.; Dury, K. US Patent, 2673860, 1954; Chem. Abstr. 1955, 49, p6312h.

226. Tundo, A. Ann. Chim. (Rome) 1956, 46, 1183.

227. Lyalin, V. V.; Grigorash, R. V.; Alekseeva, L. A.; Yagupolski, L.M. Zh. Org. Khim. 1975, 11, 1086; Chem. Abstr. 1976, 84, p23568d.

228. Grigorash, R. V.; Lyalin, V. V.; Alekseeva, L. A.; Yagupolski, L. M. Khim. Geterosikl. Soedin. 1977, 12, 1607.

229. Kunshenko, B. V.; Ilnitski, S. O.; Motnyak, L. A.; Lyalin, V. V.; Burmakov, A. I.; Yagupolski, L. M. Bull. Soc. Chim. Fr. 1986, 6, 974.

230. Gensler, W. J.; Chan, S.; Ball, D. J. Org. Chem. 1981, 46, 3407.

231. Malyshevskaya, K. A.; Laletin, A. I. Materialy Sib. Tekh. Inst. Krasnoyarsk. 1965, 67; Chem. Abstr. 1966, 65, p3979g. 
232. Krieger, A. Diss. E.T.H. - Zürich, Juris Verlag, Zürich 1961.

233. Sarzhevskaya, V. P.; Kornev, K. A.; Smirnova-Zamkova, S. E. Ukr. Khim. Zh. 1963, 29, 1076; Chem. Abstr. 1964, 60, p8144f.

234.Sarzhevskaya, V. P.; Kornev, K. A.; Smirnova-Zamkova, S.E. Ukr. Khim. Zh. 1964, 30, 499; Chem. Abstr. 1964, 61, p7114c.

235.Sarzhevskaya, V. P.; Kornev, K. A.; Smirnova-Zamkova, S. E. Ukr. Khim. Zh. 1969, 35, 390; Chem. Abstr. 1969, 71, p22399e.

236. Mitiakoudis, A. Ph.D. Thesis, Ecole Polytechnique de Grenoble, Grenoble 1984.

237. Smay, G. L. J. Mater. Sci. 1985, 20, 1494.

238. Heertjes, P. M.; Kok, G. J. Delft Progr. Rep., Ser. A 1974, 1, 59.

239. Korshak, V. V.; Izyneev, A. A.; Vdovina, L. I. Izv. Akad. Nauk SSSR, Ser. Khim. 1966, 4, 772; Chem. Abstr. 1966, 65, p9029b.

240 Braz, G. I.; Kardash, I. E.; Yakubovich, V. S.; Myasnikova, G. V.; Ardashniov, A. Ya.; Oleinik, A. F.; Pravednikov, A. N.; Yakubovich, A. Ya. Vysokomol. Soedin. Ser.8 1966, 2, 272; Chem. Abstr. 1966, 64, p16008g.

241. Chiolle, A.; Credali, L.; Gianotti, G.; Prirrini, G. Quand. Inst. Rec. Acque 1977, $22,25$.

242. Korshak, V. V.; Teplyakov, M. M.; Maksimov, A. D. Vysokomol. Soedin. Ser.B9 1967, 12, 870; Chem. Abstr. 1968, 68, p59936s.

243. Lukes, R.; Janda, M. CS Patent, 87340 (1959); Chem. Abstr. 1961, 55, p17084.

244. Manasek, Z. Khim. Volokna 1963, 6, 35; Chem. Abstr. 1964, 60, 8180a.

245. Akutin, V.; Rodivilowa, L. A.; Zhilina, R. D.; Morozova S. A.; Kovarskaya, B. M.; Shmagina, N.N. USSR.Patent, 162962, 1964; Chem. Abstr. 1964, 61, p8441e.

246. Rodivilowa, L. A.; Zhilina, R. D.; Konovalov, P. G.; Blyudeva, O. A.; Shmagina, N. N.; Vaskevich, D. N. Izv. Vyssh. Ucheb. Zaveb. Khim. Khim. Tekhnol. 11 1968, 7, 818; Chem. Abstr. 1969, 70, p4685v.

247. Fraser, A. H.; Wallenberg, F. F. J. Polym. Sci. A 1964, 2, 1137.

248. Lewis, J.C. J. Biol. Chem. 1972, 274, 1861.

249. Duennenberger, M.; Schellenbaum, M. Swiss Patent, CH 532890, 1973; Chem. Abstr. 1973, 78, p159405t.

250. Kohn, R.; Hirsch, J. Coll. Czech. Chem. Commun. 1986, 51, 1150.

251.Leskovar, P. Brit.Patent Appl., 2091998 (1982); Chem. Abstr. 1983, 98, p83590q.

252. Fraefel, W.; Lichti, H. F.; Brunetti, M. US Patent, 4383832, 1983; Chem. Abstr. 1983, 99, p43590d.

253. Fraefel, W.; Lichti, H. F.; Brunetti, M. Europ.Patent, 37381, 1981; Chem. Abstr. 1982, 96, p40959h.

254. Kamei, M.; Endo, T.; Hashimoto, Y. US Patent, 4536298, 1985; Chem. Abstr. 1986, 104, p36423v.

255. Janzowski, C.; Glaab, V.; Samimi, E.; Schlatter, J.; Eisenbrand, G. Food Chem. Toxic. 2000, 38,801 . 